\title{
Quetiapine monotherapy in acute treatment of generalized anxiety disorder: a systematic review and meta-analysis of randomized controlled trials
}

This article was published in the following Dove Press journal:

Drug Design, Development and Therapy

12 January 2016

Number of times this article has been viewed

\author{
Narong Maneeton' \\ Benchalak Maneeton' \\ Pakapan Woottiluk ${ }^{2}$ \\ Surinporn Likhitsathian' \\ Sirijit Suttajit' \\ Vudhichai Boonyanaruthee' \\ Manit Srisurapanont ${ }^{1}$ \\ 'Department of Psychiatry, Faculty \\ of Medicine, Chiang Mai University, \\ Chiang Mai, Thailand; ${ }^{2}$ Psychiatric \\ Nursing Division, Faculty of Nursing, \\ Chiang Mai University, Chiang Mai, \\ Thailand
}

Background: Some studies have indicated the efficacy of quetiapine in the treatment of generalized anxiety disorder (GAD).

Objective: The purpose of this study was to systematically review the efficacy, acceptability, and tolerability of quetiapine in adult patients with GAD.

Methods: The SCOPUS, MEDLINE, CINAHL, Cochrane Central Register of Controlled Trials, and ClinicalTrials.gov databases were searched in April 2015. All randomized controlled trials (RCTs) of GAD were considered to be included in this meta-analysis. All RCTs of quetiapine in GAD patients providing endpoint outcomes relevant to severity of anxiety, response rate, remission rate, overall discontinuation rate, or discontinuation rate due to adverse events were included. The version reports from suitable clinical studies were explored, and the important data were extracted. Measurement for efficacy outcomes consisted of the mean-changed scores of the rating scales for anxiety, and response rate.

Results: A total of 2,248 randomized participants in three RCTs were included. The pooled mean-changed score of the quetiapine-treated group was greater than that of the placebo-treated group and comparable to selective serotonin reuptake inhibitors (SSRIs). Unfortunately, the response and the remission rates in only 50 and $150 \mathrm{mg} /$ day of quetiapine-XR (extended-release) were better than those of the placebo. Their response and remission rates were comparable to SSRIs. The rates of pooled overall discontinuation and discontinuation due to adverse events of quetiapine-XR were greater than placebo. Only the overall discontinuation rate of quetiapine-XR at 50 and $150 \mathrm{mg} /$ day and the discontinuation rate due to adverse events of quetiapine-XR at $50 \mathrm{mg}$ /day were comparable to SSRIs.

Conclusion: Based on this meta-analysis, quetiapine-XR is efficacious in the treatment of GAD in adult patients. Despite its low acceptability and tolerability, the use of 50-150 mg/day quetiapine-XR for adult GAD patients may be considered as an alternative treatment. Further well-defined studies should be conducted to warrant these outcomes.

Keywords: quetiapine, generalized anxiety disorder, efficacy, acceptability, tolerability

\section{Background}

Generalized anxiety disorder (GAD) is a common psychiatric disorder with a 1-year prevalence rate of $1.2 \%-1.9 \%$ and lifetime prevalence rate of $4.3 \%-5.9 \%{ }^{1,2}$ Since it is a disabling and chronic condition, it is a major burden for the individual, family, and health care services. ${ }^{1,2}$ As a rule, cognitive-behavioral therapy is effective in the treatment of GAD. ${ }^{2}$ However, some GAD patients do not respond to cognitive-behavioral therapy because of severity and chronicity of GAD, presence of comorbidity, stressful events, lack of patient motivation, and resistance to therapy. ${ }^{3}$ Therefore, pharmacological treatment may be essential for those patients.
Correspondence: Narong Maneeton Department of Psychiatry, Faculty of Medicine, Chiang Mai University, 1 I0 Intawaroros Road, Sriphum, Amphur Muang, Chiang Mai 50200, Thailand

Tel +66 53935422

Fax +66 53935426

Email narong.m@cmu.ac.th 
Antidepressants are effective in the treatment of GAD.,5 Previous evidences suggest that selective serotonin reuptake inhibitors (SSRIs), including paroxetine, ${ }^{6-9}$ sertraline, ${ }^{10,11}$ citalopram, ${ }^{12}$ and escitalopram, ${ }^{13,14}$ are effective in the treatment of GAD. In addition, several studies also demonstrate that serotonin norepinephrine reuptake inhibitors (SNRIs) such as venlafaxine ${ }^{15}$ and duloxetine, ${ }^{16}$ as well as dopamine norepinephrine reuptake inhibitors such as bupropion, ${ }^{17}$ are possibly effective treatments in GAD. However, numerous GAD patients do not achieve remission or response despite adequate dose and duration of SSRIs and SNRIs.

Regularly, the rates of response and remission for GAD patients treated with SSRIs are $60 \%-68 \%$ and $30 \%-36 \%,{ }^{8,11}$ respectively. In addition, GAD patients treated with SNRIs have demonstrated response and remission rates of $56 \%-58 \%$ and $31 \%-38 \%,{ }^{18,19}$ respectively. Additionally, several GAD patients discontinue the antidepressant therapy. Based on recent evidences, the overall discontinuation rates for SSRIs and SNRIs are $20 \%-23 \%{ }^{13,20}$ and $25 \%-45 \%,{ }^{20-22}$ respectively, while the discontinuation rates due to adverse events for SSRIs and SNRIs are $7 \%-9 \%{ }^{13,20}$ and $11 \%-20 \%{ }^{20-22}$ respectively. The fact that a large number of GAD patients withdrew from those studies may imply that acceptance, as measured by the rates of overall discontinuation and tolerability, as a measure of discontinuation rate due to adverse events, for SSRIs and SNRIs, appears to be limited. The low acceptability and tolerability of SSRIs and SNRIs are possibly associated with unfavorable side effects of SSRIs and SNRIs including nausea and sexual dysfunction, as well as slow onset of their action. ${ }^{23-25}$

Sleep difficulties included in the diagnostic criteria for $\mathrm{GAD}^{26}$ is another major concern in those patients. Insomnia is highly prevalent in GAD patients, and it often persists although the disorder is successfully treated..$^{27-29}$ Therefore, several patients seek an additional treatment to alleviate this symptom. Although benzodiazepine, having faster onset of effect in $\mathrm{GAD},{ }^{30}$ is effective in the treatment of insomnia in GAD patients, ${ }^{27}$ use of this active drug may increase numerous risks, including drowsiness, falls, confusion, impaired memory and incoordination. ${ }^{31}$ Additionally, long-term use of benzodiazepine potentially increases substance abuse or dependence. ${ }^{31}$ However, SSRIs, particularly fluoxetine, are associated with sleep difficulty in the early-treatment of GAD. ${ }^{32}$ Hence, alternative medication has more effects in both GAD and sleep difficulty, and less potential drug abuse and dependence may be beneficial in this disorder.

Quetiapine, a dibenzothiazepine derivative, is rapidly absorbed after oral administration. Its absorption is minimally affected by food. Its pharmacokinetics do not appear to be changed by cigarette smoking. ${ }^{33}$ The extended-release (XR) quetiapine fumarate, a once-daily formulation, is relatively similar in pharmacokinetics with the immediate release quetiapine in terms of the overall absorption and elimination. ${ }^{34}$

Recently, there have been several clinical studies that have shown the efficacy of quetiapine in the treatment of GAD. ${ }^{35-37}$ Similar to the majority of pharmacological agents utilized to treat anxiety disorder which are associated with serotonergic and/or noradrenergic neurotransmission, the possible explanation of the effect of quetiapine and its metabolite for GAD may be associated with the action on dopaminergic, serotoninergic, and noradrenergic systems or their combined effects. ${ }^{37}$ Quetiapine, as well as its active metabolite, the so-called $\mathrm{N}$-desalkylquetiapine (norquetiapine) have moderate-tohigh affinity for various central serotonergic, including $5 \mathrm{HT}_{2 \mathrm{~A}}$, and dopaminergic, including $\mathrm{D}_{2}$, receptors. ${ }^{38,39}$

Different from other serotonin dopamine antagonists at clinically relevant doses, norquetiapine has a potential propensity for inhibition of the norepinephrine transporter contributed property with tricyclic antidepressants and SNRIs, and a moderate-to-high affinity for $5 \mathrm{HT}_{1 \mathrm{~A}}, 5 \mathrm{HT}_{2 \mathrm{~A}}$, and $5 \mathrm{HT}_{2 \mathrm{C}}$ receptors which share some properties with SSRIs, ${ }^{39-43}$ which is possibly associated with its efficacy for the treatment of depression as well as GAD. Additionally, quetiapine has a potent antagonist effect on $5-\mathrm{HT}_{2 \mathrm{~A}}$ receptor which explains its sedative effect. ${ }^{39,42,44-46}$ Therefore, use of quetiapine could be an advantage in GAD patients with a sleep problem.

Recent evidences from randomized controlled trials (RCTs) have shown that quetiapine is efficacious in the treatment of GAD ${ }^{35-37}$ Since such studies have limited sample sizes, meta-analysis, a more powerful method in determining the true effect size, is a possible strategy to verify the efficacy and acceptability of quetiapine in the treatment of GAD.

This study aims to systematically review the efficacy, acceptability, and tolerability of quetiapine in patients with GAD. Its efficacy was determined by relying on the measures of the pooled mean-changed scores of the rating scales for $\mathrm{GAD}$, as well as the response and remission rates, while its acceptability and tolerability were measured, respectively, by the overall discontinuation rate and the discontinuation rate due to adverse events. Only the RCTs of quetiapine in those patients were included in this meta-analysis.

\section{Methods}

\section{Types of studies}

All relevant RCTs were considered.

\section{Types of participants}

All adult patients, aged 18-65 years and diagnosed with GAD by using any set of criteria, were eligible. 


\section{Types of interventions}

The type of intervention in this meta-analysis was quetiapine as monotherapy compared with placebo or antidepressants in adult GAD patients. The doses, forms, and frequency of treatments were not restricted. Additionally, sub-analysis of the 50,150 , and $300 \mathrm{mg} /$ day of quetiapine was performed to examine whether the dose affected its efficacy, acceptability, and tolerability.

\section{Types of outcome measures}

\section{Primary outcome measures}

The primary outcome measure was mean change score of a standardized anxiety rating scale (Hamilton Anxiety Rating Scale $[\text { HAM-A] })^{47}$

\section{Secondary outcome measures}

The secondary outcome measures consisted of:

1. Response rate which was defined by each trial.

2. Remission rate as defined by individual study.

3. Clinical Global Impression (CGI).

3.1 Mean change scores of the CGI-Severity (CGI-S).

3.2 Mean endpoint score of the CGI-Improvement (CGI-I).

4. Mean change scores of the sleep quality standardized scale, the Pittsburgh Sleep Quality Index (PSQI).

5. Mean change scores of a depression standardized rating scale, Montgomery-Åsberg Depression Rating Scale (MADRS).

6. Discontinuation rates.

6.1 Overall discontinuation rate.

6.2 Discontinuation rate due to adverse events.

\section{Information sources}

The searched databases consisted of SCOPUS, MEDLINE, CINAHL, and Cochrane Central Register of Controlled Trials databases, which were searched in April 2015. Since the first publication regarding quetiapine was in 1991 in MEDLINE, we planned to search those publications from January 1991 to April 2015. Those searches were limited to studies in humans. Additional search resources consisted of ClinicalTrials.gov, EU Clinical Trials Register, and AstraZeneca Clinical Trials databases. The relevant references of any article given by any method were inspected. All accordant RCTs were taken into account. However, language restriction was not applied.

\section{Searches}

To sensitize the optimal identification of the RCTs, the searching method for MEDLINE was restricted to the following words and phrases: [(quetiapine) OR (seroquel)] AND [(generalized anxiety disorder)]. Similar search strategies were applied for the rest of the databases.

\section{Study selection}

To determine whether those studies complied with the eligibility criteria described earlier, the reviewers (NM and BM) individually examined all the abstracts collected via electronic database search. When the full-text versions of the relevant articles were gathered, the reviewers (NM and BM) individually assessed them. In case of disputes, a conclusion was arrived at by consensus.

\section{Data collection process}

Initially, the first reviewer (NM) extracted all the data from the full-version articles and turned the extracted data into the developed extraction form. Then, those extracted data were carefully rechecked by the second reviewer (BM). Accordingly, any dispute between two reviewers was resolved by consensus. If any disagreements between two reviewers could not be resolved, they were finally resolved based on the third reviewer's judgment.

\section{Data items}

The extracted data collected from each clinical trial consisted of the following: 1) important information applied for quality assessments; 2) basic characteristics data regarding population, diagnostic criteria, study designs, and eligibility/ ineligibility criteria; 3 ) forms, doses, and treatment duration of quetiapine versus placebo; 4) interesting outcomes; and 5) intention-to-treat results.

\section{Risk of bias in individual studies}

The internal validity (quality) assessments for all eligible clinical trials were performed by two reviewers (NM and BM). Relying on the Cochrane Collaboration quality assessment, the measurements for the risk of bias were composed of the following: 1) sequence generation (randomization); 2) allocation concealment; 3) blinding of participants, personnel, and outcomes; 4) incomplete outcome data; 5) selective outcome reporting; and 6) other biases. ${ }^{48}$

\section{Summary measures}

Efficacy, acceptability, and tolerability were the interesting outcomes. The measure of efficacy was based on the scores of endpoint or the mean-changed scores rated on a standardized GAD scale and the response rate defined by any set of criteria. Additionally, sleep and depression scales were also evaluated. Based on the previous meta-analysis, this meta-analysis 
defined acceptability as measured by the overall discontinuation rate. ${ }^{49}$ Similar to a previous meta-analysis, the measure of tolerability, related to the side effects of the medications, ${ }^{50}$ was derived from the discontinuation rate due to adverse events. To determine whether dose affected efficacy, the pooled analysis of the 50, 150, and $300 \mathrm{mg}$ quetiapine may occur.

\section{Statistical analysis and synthesis of results}

Either a weighted mean difference (WMD) or a standardized mean difference (SMD) with 95\% confidence interval (CI) is calculated as the mean difference between the comparison groups divided by an estimate of the within-group standard deviation (SD). Mean differences, with 95\% CI, were used to synthesize all continuous data. When the same outcomes are measured by various rating scales across studies, ${ }^{51}$ it is not possible to directly compare or combine those clinical study outcomes. Since the effect is expressed as an SMD, which has no units, it is possible to compare or combine those outcomes. In case the same rating scales are applied, a WMD, direct comparison, or a combination of the clinical outcomes can be used. In this meta-analysis, either the WMDs or the SMDs were applied for calculation, based on whether the eligible study used similarly measured or differently measured instruments. If the SD of the endpoint and the mean-changed score cannot be made available, the estimation may be done by using any of the statistical analyses or by direct substitution. ${ }^{52}$ The statistical method for combining results of multiple studies by an inverse-variance of the effect estimate, which gives weight to the influence of each study, was applied for calculation of the pooled mean-endpoint or change scores with $95 \%$ CIs. $^{48}$

Relative risk (RR), with 95\% CI was used to synthesize all dichotomous data. When the RR is exactly 1 , it suggests that a difference in the outcomes does not occur between the intervention and the control groups. In cases where RR is more or less than 1 , it is a possible indication that the intervention, respectively, increases or decreases the risk of the outcomes. In this meta-analysis, we used RRs to compare the response rates, the remission rates, the overall discontinuation rates, and the discontinuation rates due to adverse events between the two groups. All pooled RRs of dichotomous data with $95 \%$ CIs were estimated by using the Mantel-Haenszel technique. ${ }^{48}$

In systematic reviews, either the fixed or the random effect model is applied for the synthesis of data. According to the fixed effect model, it is speculated that the true effect size is the same in all studies in all the included clinical trials, and the summary effect is the estimation of the common effect size. Therefore, when each study is weighted, the results of the smaller studies can be ignored since the better outcomes about the same effect size in the larger studies are provided. In this event, a fixed effect model could be applied. In fact, the assumption of one true effect size is generally impossible. Even though all the included clinical trials were relatively homogenous, it cannot be concluded that they are absolutely identical. As a result, a random effect model, which assumes that the true effect size varies across the studies, was decided upon in the synthesis of all the data in this meta-analysis. The RevMan 5.1 (The Nordic Cochrane Centre, Copenhagen, Denmark) was used to synthesize all the data in this meta-analysis.

\section{Risk of bias across studies}

For the assessment of reporting bias, a funnel plot was applied. A funnel plot is a simple scatter plot of the treatment effect calculated from individual studies against a measure of each study's size. In case of the absence of bias, the plot should resemble a symmetrical inverted funnel. ${ }^{53}$

\section{Test of heterogeneity}

A test of heterogeneity is able to determine the similarities of clinical outcomes. When the test was carried out in this meta-analysis, we hypothesized that the effect size had differences due to the differences in the quality of methodology in individual clinical trials. The outcomes of all the trials were examined as to whether they were higher and different from the anticipated outcomes by chance alone. To determine those outcomes, we inspected them by displaying them as graphs and also applied the test of heterogeneity. In case of an $I^{2}$ of $50 \%$ or more, those outcomes were recognized as having significant heterogeneity.

\section{Results \\ Study selection}

Based on the search carried out of such databases, it was found that there was a total of 407 citations (SCOPUS $=301$, MEDLINE $=46$, CINAHL $=10$, Cochrane Central Register of Controlled Trials $=28$, $\underline{\text { ClinicalTrials.gov }}=21$, and EU Clinical Trials Register =1) (Figure 1). After the duplicates were discarded, 369 citations persisted. When their titles and abstracts were assessed, 15 citations were observed to still meet the eligibility criteria. Therefore, full papers of 15 citations were inspected. Of the 15 citations, four were excluded from this meta-analysis since two were pooled analyses $^{54,55}$ and the others were maintenance studies. ${ }^{37,56}$ 


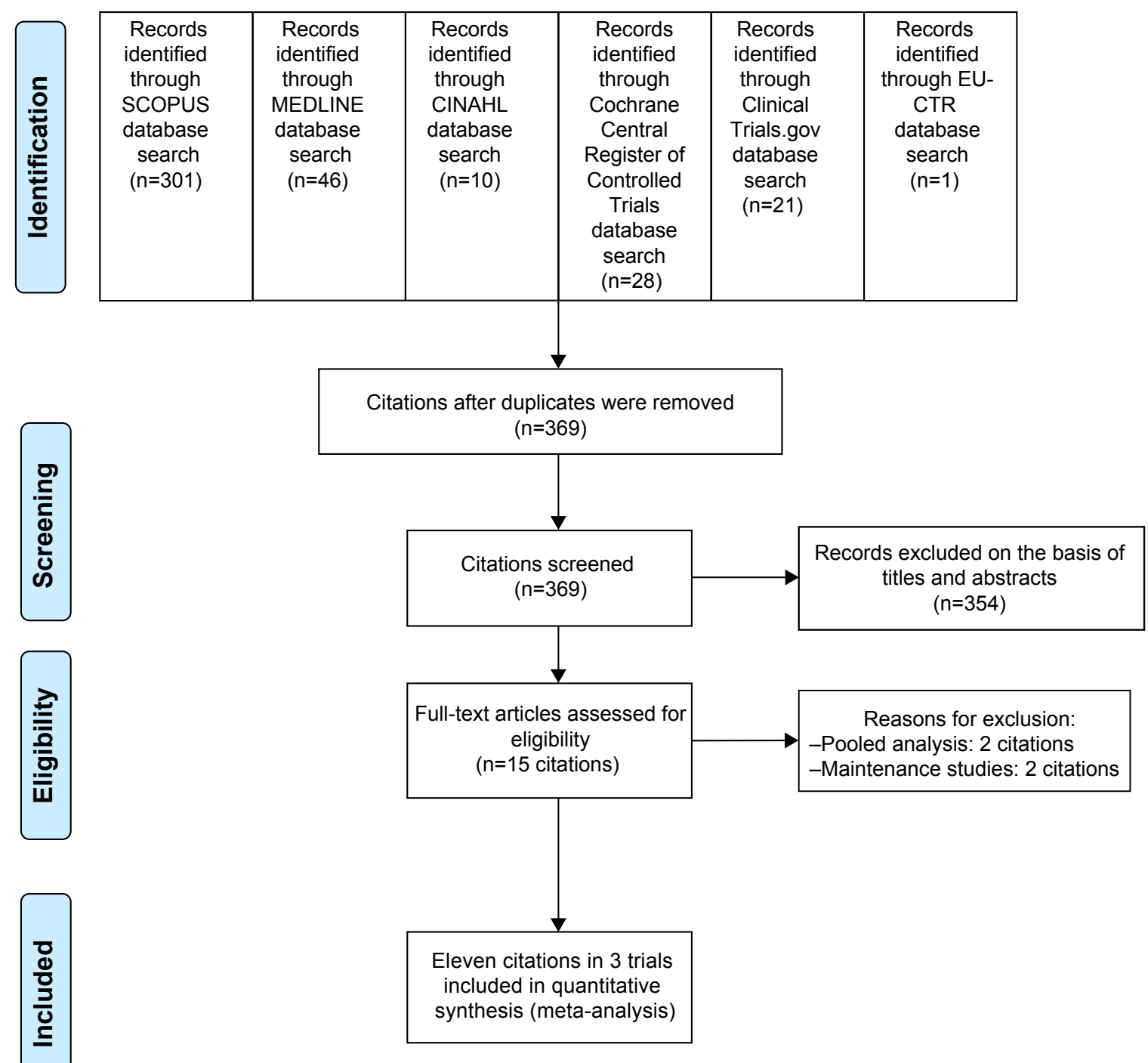

Figure I The flow diagram of the study.

Abbreviation: EU-CTR, EU Clinical Trials Register.

Consequently, a total of eleven citations in three clinical trials were included in this meta-analysis. ${ }^{35,36,43,54,57-62}$ However, a relevant or unpublished study fitting the eligibility criteria was not detected.

\section{Study characteristics}

All eligible trials included GAD patients with HAM-A total scores $\geq 20$ with item 1 (anxious mood) and item 2 (tension) scores $\geq 2$ (administered using the Structured Interview Guide for the HAM-A), MADRS total scores $\leq 16$, and CGI-S scores $\geq 4$ at enrollment and randomization. The exclusion criteria of all trials consisted of diagnosis of any Diagnostic and Statistical Manual of Mental Disorders, Fourth edition text revision (DSM IV-TR) Axis I disorder other than GAD within 6 months prior to enrollment or any
DSM IV-TR Axis II disorder that could interfere with the patient's ability to participate in the study, a current serious suicidal or homicidal risk or MADRS item 10 (suicidality) scores $\geq 4$ or a suicide attempt during the 6 months prior to enrollment, substance or alcohol abuse within 6 months prior to enrollment or a clinically significant deviation from reference ranges in clinical laboratory test results. ${ }^{35,36,43}$ Two studies excluded patients with any clinically relevant disease, including renal or hepatic impairment, significant coronary artery disease or cerebrovascular disease. ${ }^{36,43}$ All had study duration of 10-14 weeks. All the participants were randomized to receive either quetiapine-XR or placebo treatment. The criteria of response rate and remission were the same in all the included trials. The dose of quetiapine ranged from 50 to $300 \mathrm{mg} /$ day (Table 1). The demographic and clinical 


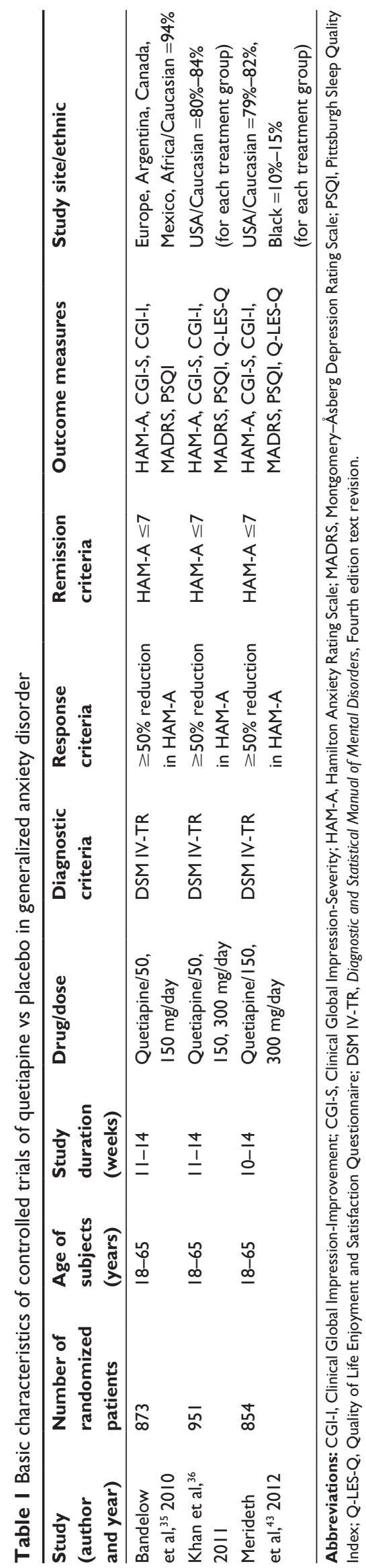

characteristics of the quetiapine-treated group versus the placebo-treated group were generally well matched across the three studies. . $^{35,36,43}$

A total of 2,678 randomized patients were included in this meta-analysis. The number of patients who took at least one dose of study drug and had a randomization HAM-A assessment and at least one valid HAM-A assessment after randomization (modified intention-to-treat [MITT]) was 2,588. All the eligible subjects met the GAD criteria of the DSM IV-TR. Based on the MITT population, the mean (SD) ages of the quetiapine-treated group and the placebo-treated group were found to be 40.16 (11.98) years and 41.01 (11.70) years, respectively. Each participant of the included studies randomly received either quetiapine-XR or placebo. The essential characteristics of the included studies are presented in Table 1.

All clinical trials presented the HAM-A as the primary measure of anxiety severity. Therefore, the WMDs of the mean-changed scores were estimated and synthesized. All the clinical studies reported the remission, response, and discontinuation rates.

\section{Risk of bias within studies}

The generated sequence for randomization, allocation concealment, and techniques of randomization and double blindness was used in all the clinical studies. Unfortunately, two included studies did not clearly explain the blinding of outcome assessment and did not report the additional measures (Simpson-Angus Scale, Barnes Akathisia Rating Scale, Changes in Sexual Functioning Questionnaire) which were included in their protocols ${ }^{36,43}$ (Table 2). The MITT analysis was applied in all the trials.

\section{Synthesis of results Efficacy}

\section{Quetiapine versus placebo}

The significance of heterogeneity was not observed in the rates of response, remission, and improvement (CGI-I),

Table 2 Summary of risk of bias in clinically controlled trials of quetiapine vs placebo in generalized anxiety disorder

\begin{tabular}{llllllll}
\hline Study & \multicolumn{7}{l}{ Issue of bias } \\
\cline { 2 - 7 } & I & $\mathbf{2}$ & $\mathbf{3}$ & $\mathbf{4}$ & $\mathbf{5}$ & $\mathbf{6}$ & $\mathbf{7}$ \\
\hline Bandelow et a $^{35}$ & $\mathrm{~L}$ & $\mathrm{~L}$ & $\mathrm{~L}$ & $\mathrm{~L}$ & $\mathrm{~L}$ & $\mathrm{~L}$ & $\mathrm{~L}$ \\
Khan et a $^{36}$ & $\mathrm{~L}$ & $\mathrm{~L}$ & $\mathrm{~L}$ & $\mathrm{U}$ & $\mathrm{L}$ & $\mathrm{U}$ & $\mathrm{L}$ \\
Merideth et al $^{43}$ & $\mathrm{~L}$ & $\mathrm{~L}$ & $\mathrm{~L}$ & $\mathrm{U}$ & $\mathrm{L}$ & $\mathrm{U}$ & $\mathrm{L}$ \\
\hline
\end{tabular}

Notes: I= adequate sequence generation of randomization (selection bias); $2=$ allocation concealment (selection bias); $3=$ blinding of participants and personnel (performance bias); $4=$ blinding of outcome assessment (detection bias); $5=$ incomplete outcome data (attrition bias); $6=$ selective reporting (reporting bias); $7=$ other sources of bias (other bias); $\mathrm{U}=$ unclear; and $\mathrm{L}=$ low risk of bias. 
except for the WMDs for the pooled mean-changed scores of the HAM-A and the CGI-S. The pooled WMD for the mean-changed score of the HAM-A in the quetiapine-treated group was significantly greater than that of the placebo-treated group (WMD [95\% CI] of -2.19 $\left.[-2.94,-1.45], I^{2}=50 \%\right)$. The mean-changed scores of the HAM-A in all doses of quetiapine were also greater than that of placebo (Figure 2). Although the overall pooled response and remission rates of the quetiapine-treated group were also significantly greater than the rates of the placebo-treated group, with RRs (95\% CI) of 1.24 (1.16, $1.32), I^{2}=7 \%$ and RRs ( $\left.95 \% \mathrm{CI}\right)$ of $1.27(1.13,1.42), I^{2}=7 \%$, respectively, only the response and remission rates of quetiapine at 50 and $150 \mathrm{mg} /$ day were significantly greater than that of placebo (Figures 3 and 4). Based on the response rate, the number needed to treat $(95 \% \mathrm{CI})$ was $8.40(6.10$, 13.58). Considered in the CGI-S, its pooled WMD for the mean-changed score in the quetiapine-treated group was significantly greater than that of the placebo-treated group (WMD [95\% CI] of $-0.26[-0.40,-0.13], P=77 \%$ ). Similar to the response and remission rates, only quetiapine 50 and $150 \mathrm{mg}$ /day had greater mean-changed scores of CGI-S than that of placebo (Figure 5). The pooled improvement rate (CGI-I $=1,2$ ) of the quetiapine-treated group was significantly greater than the placebo-treated group with RRs $(95 \% \mathrm{CI})$ of $1.17(1.10,1.24), I^{2}=0 \%$. However, its significant difference was noted in only the quetiapine 50 and $150 \mathrm{mg} /$ day (Figure 6).

\section{Quetiapine versus SSRIs}

Significant heterogeneity was not found in the rates of response, remission, and improvement (CGI-I =1, 2), except for the WMDs for the pooled mean-changed scores of the HAM-A and the CGI-S. The pooled WMD for the meanchanged score of the HAM-A in the quetiapine-treated and SSRIs-treated groups was not significantly different (WMD $[95 \% \mathrm{CI}]$ of $-0.68[-1.73,0.36], P=52 \%$ ) (Figure 7). Similarly, the pooled response and remission rates between two groups were not significantly different, with RRs $(95 \% \mathrm{CI})$ of 1.04 $(0.95,1.14), I^{2}=28 \%$ and RRs of $(95 \% \mathrm{CI})$ of 1.00 (0.85, 1.17), $I^{2}=34 \%$, respectively (Figures 8 and 9 ). Based on the CGI-S, its pooled WMD for the mean-changed score between both groups was also not significantly different (WMD [95\% $\mathrm{CI}]$ of $-0.06[-0.23,0.11], P^{2}=52 \%$ ) (Figure 10). The pooled improvement rate, measured by the CGI-I, between the two groups did not show a significant difference with RRs (95\% CI) of $1.03(0.96,1.10), I^{2}=0 \%$ (Figure 11).

\section{Sleep quality Quetiapine versus placebo}

Based on the sleep quality, it was observed that the pooled WMD for the mean-changed score of the PSQI of the quetiapine-treated group was significantly greater than that of the placebo-treated group (WMD [95\% CI] of -1.20 $\left.[-1.63,-0.77], I^{2}=69 \%\right)$. The mean-changed scores of quetiapine treatment in all doses were also significantly higher than that of placebo (Figure 12).

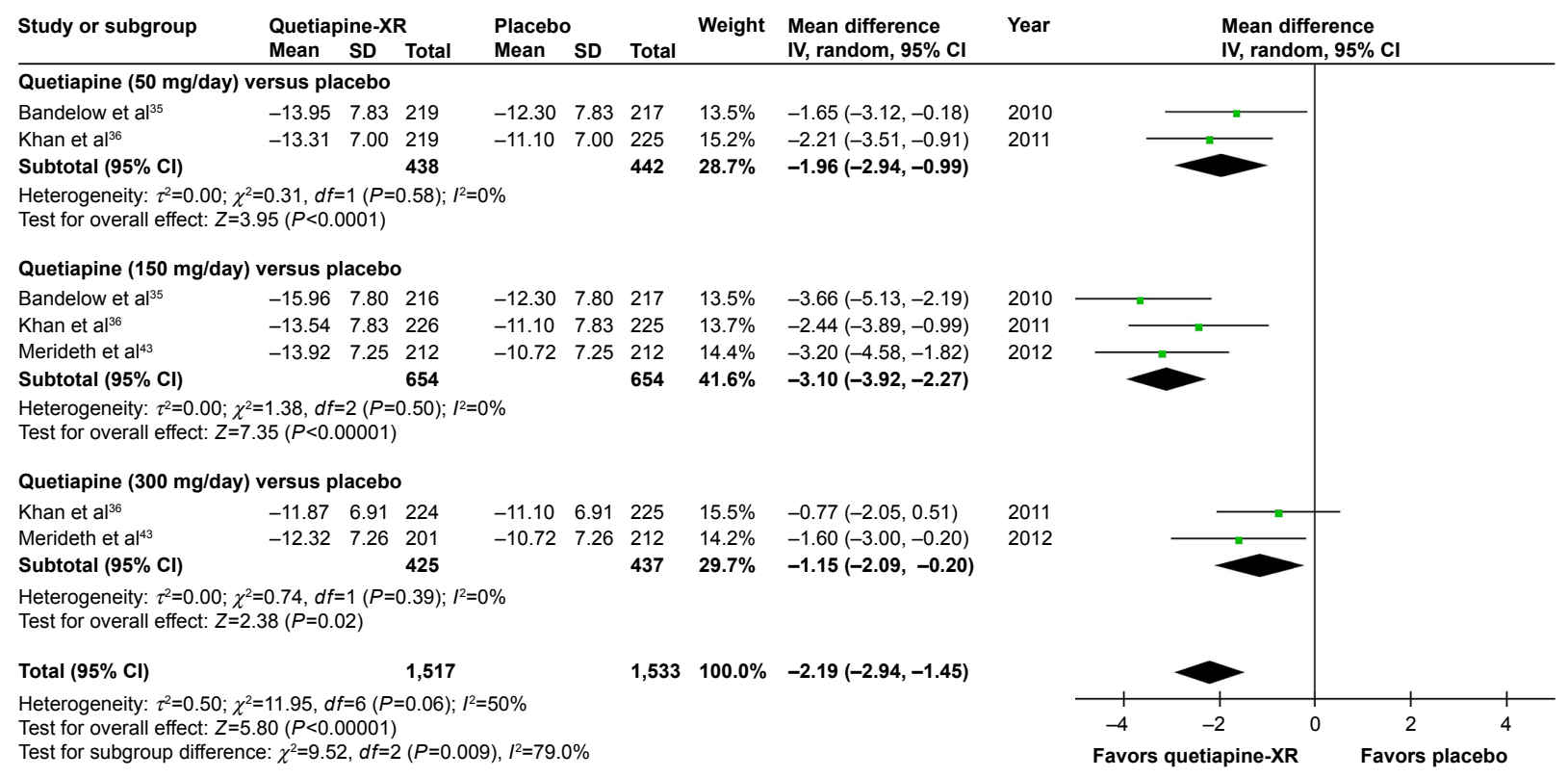

Figure 2 The forest plot of comparison of the mean changes from the baseline of the HAM-A scores (95\% confidence interval) of quetiapine vs placebo in GAD. Abbreviations: $\mathrm{Cl}$, confidence interval; IV, inverse variance; $d f$, degrees of freedom; GAD, generalized anxiety disorder; SD, standard deviation; $\mathrm{XR}$, extended-release. 


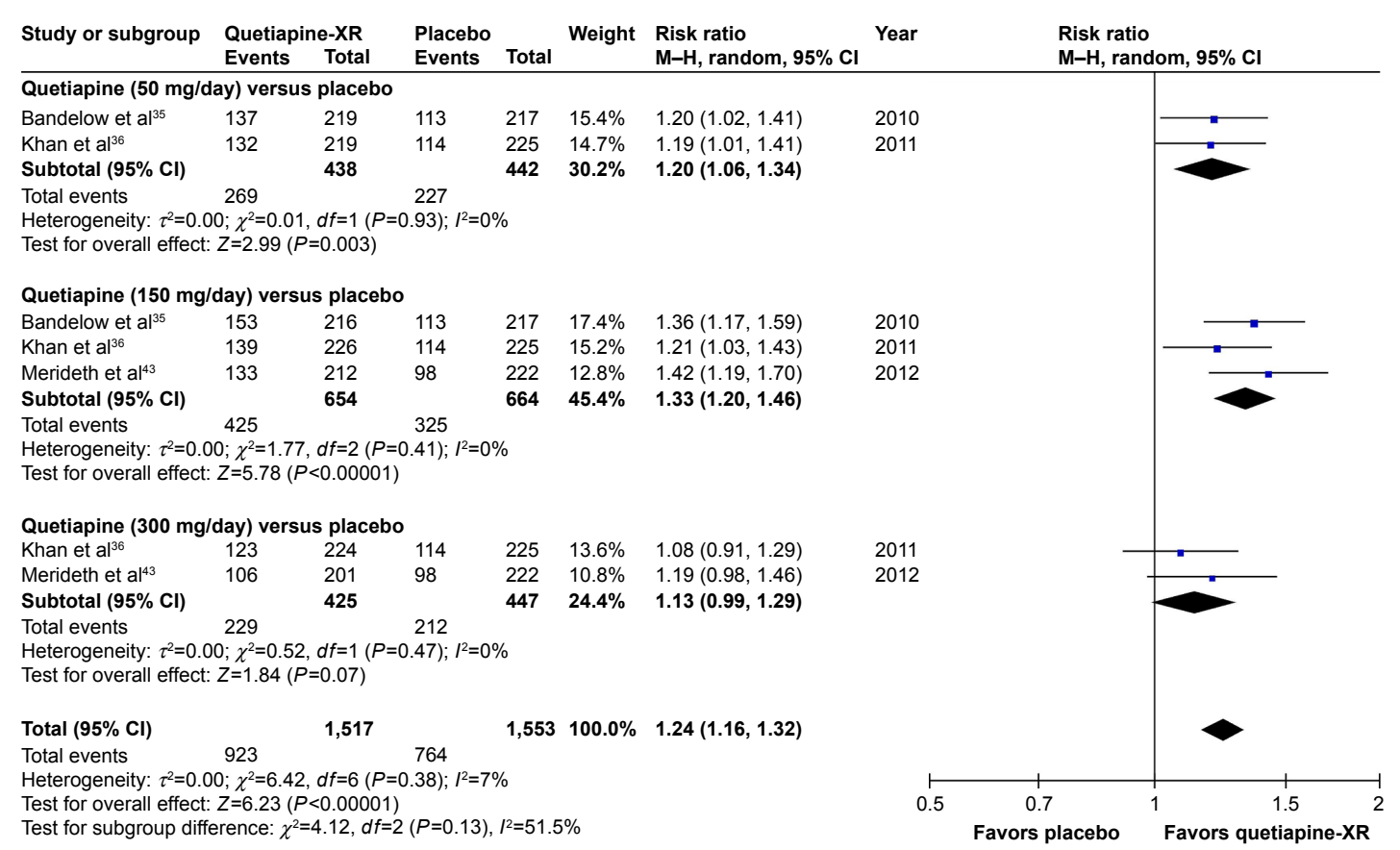

Figure 3 The forest plot of comparison of relative risks ( $95 \%$ confidence interval) for the clinical response rates of quetiapine vs placebo in GAD.

Abbreviations: $\mathrm{Cl}$, confidence interval; $d f$, degrees of freedom; GAD, generalized anxiety disorder; $\mathrm{M}-\mathrm{H}$, Mantel-Haenszel; $\mathrm{XR}$, extended-release.

\section{Quetiapine versus SSRIs}

Based on the sleep quality, it was noted that the pooled WMD for the mean-changed score of the PSQI of the quetiapine-treated group was significantly greater than that of the SSRIs-treated group (WMD $[95 \% \mathrm{CI}]$ of $-1.27[-1.86,-0.68], P^{2}=61 \%$ ). However, only mean-changed scores of quetiapine 50 and $150 \mathrm{mg} /$ day were significantly greater than that of SSRIs (Figure 13).

\section{Depression}

Quetiapine versus placebo

The pooled WMD for the mean-changed score of the MARDS in the quetiapine-treated group was significantly greater than that of the placebo-treated group (WMD [95\% CI] of $\left.-1.60[-2.21,-1.00], I^{2}=58 \%\right)$. Additionally, the mean-changed scores for all doses of quetiapine

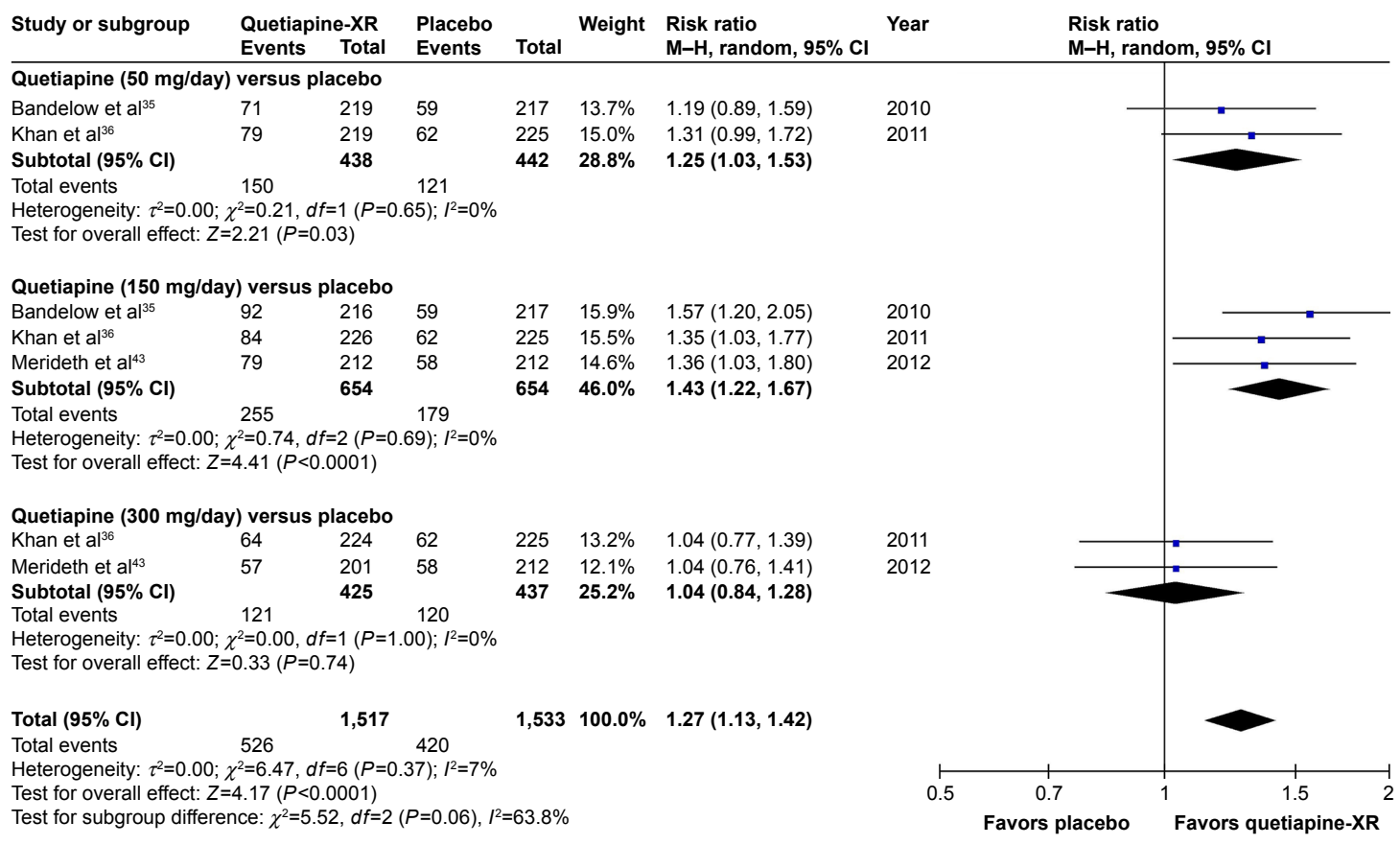

Figure 4 The forest plot of comparison of relative risks (95\% confidence interval) for the clinical remission rates of quetiapine vs placebo in GAD.

Abbreviations: $\mathrm{Cl}$, confidence interval; $d f$, degrees of freedom; GAD, generalized anxiety disorder; $M-H$, Mantel-Haenszel; XR, extended-release. 


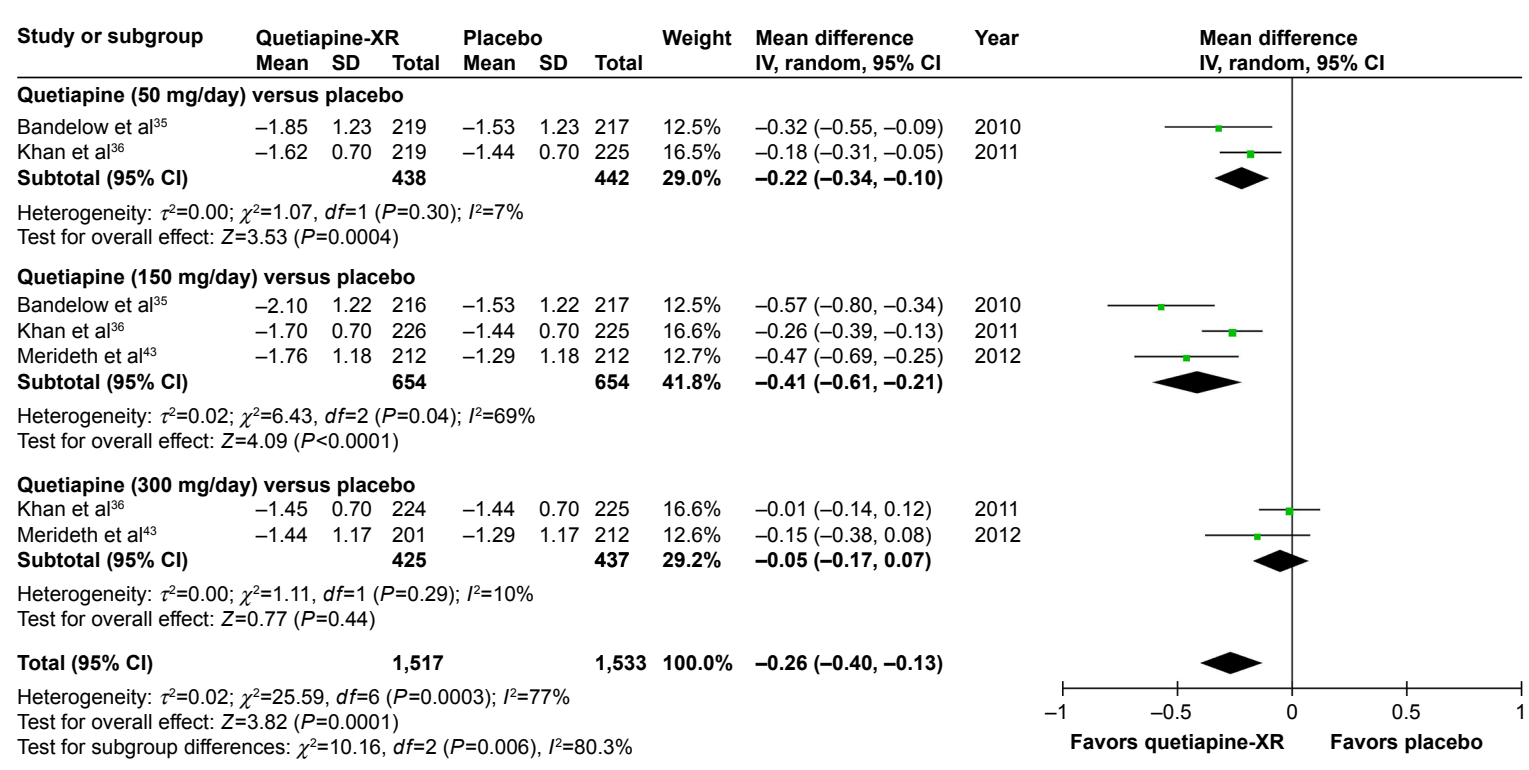

Figure $\mathbf{5}$ The forest plot of comparison of the mean changes from the baseline of the CGI-S scores ( $95 \%$ confidence interval) of quetiapine vs placebo in GAD. Abbreviations: $\mathrm{Cl}$, confidence interval; IV, inverse variance; $d f$, degrees of freedom; GAD, generalized anxiety disorder; SD, standard deviation; CGI-S, Clinical Global Impression-Severity; XR, extended-release.

treatment were significantly greater than that of the placebo (Figure 14).

\section{Quetiapine versus SSRIs}

The pooled WMD for the mean-changed score of the MARDS between the two groups was not significantly different (WMD $[95 \% \mathrm{CI}]$ of $-0.32[-1.15,0.52], l^{2}=62 \%$ ) (Figure 15).

\section{Overall discontinuation rate (acceptability) Quetiapine versus placebo}

Significant heterogeneity was not found in the overall discontinuation rate. Since the pooled overall discontinuation rate of the quetiapine-treated group was significantly greater than that of the placebo-treated group, with RRs (95\% CI) of $1.33(1.17,1.52), I^{2}=27 \%$, it suggests that acceptability

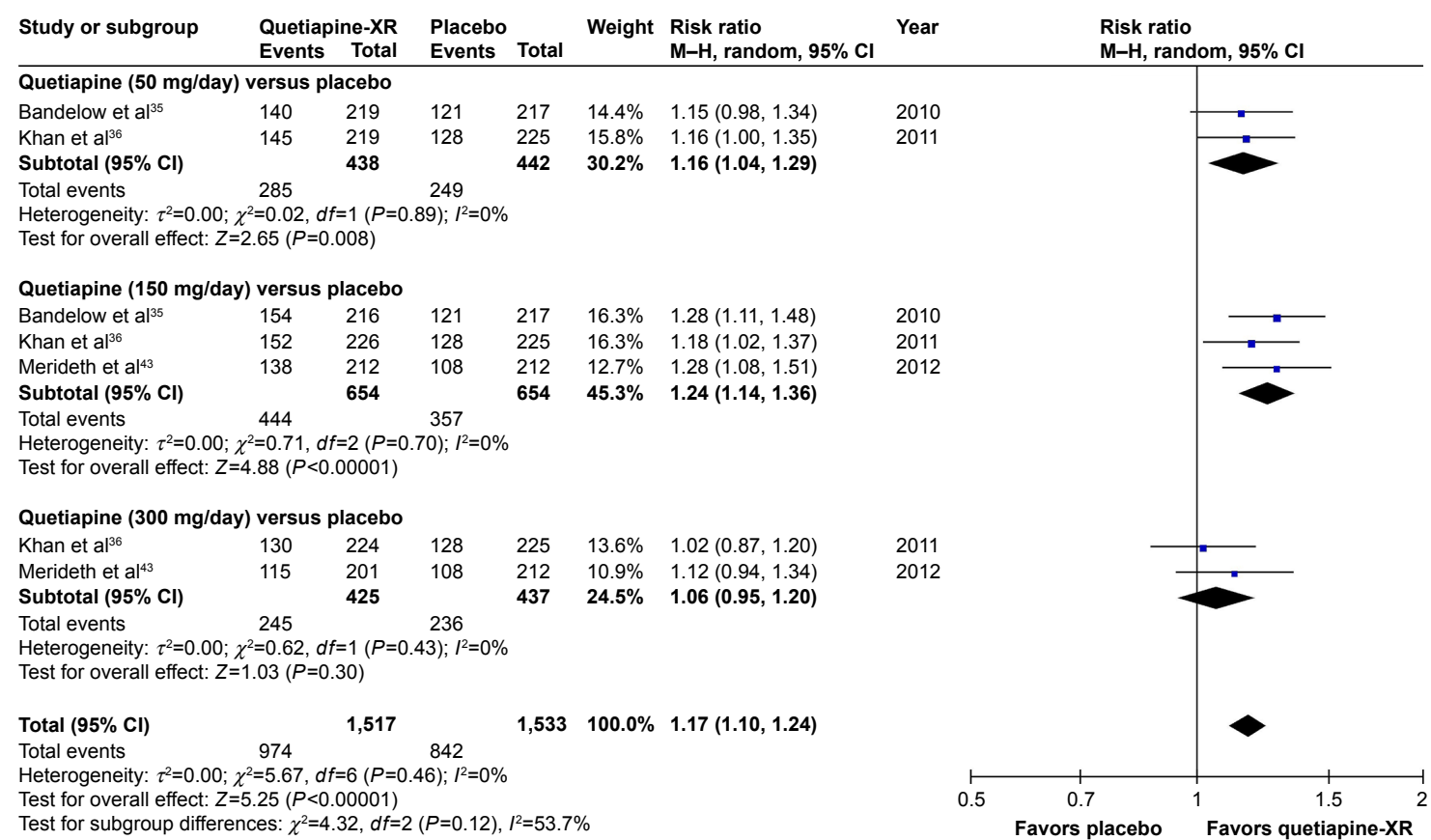

Figure 6 The forest plot of comparison of relative risks (95\% confidence interval) for the clinical improvement rate (CGI-I =I, 2) of quetiapine vs placebo in GAD. Abbreviations: $\mathrm{Cl}$, confidence interval; $\mathrm{df}$, degrees of freedom; GAD, generalized anxiety disorder; $\mathrm{M}-\mathrm{H}$, Mantel-Haenszel; CGI-I, Clinical Global Impression-Improvement; $\mathrm{XR}$, extended-release. 


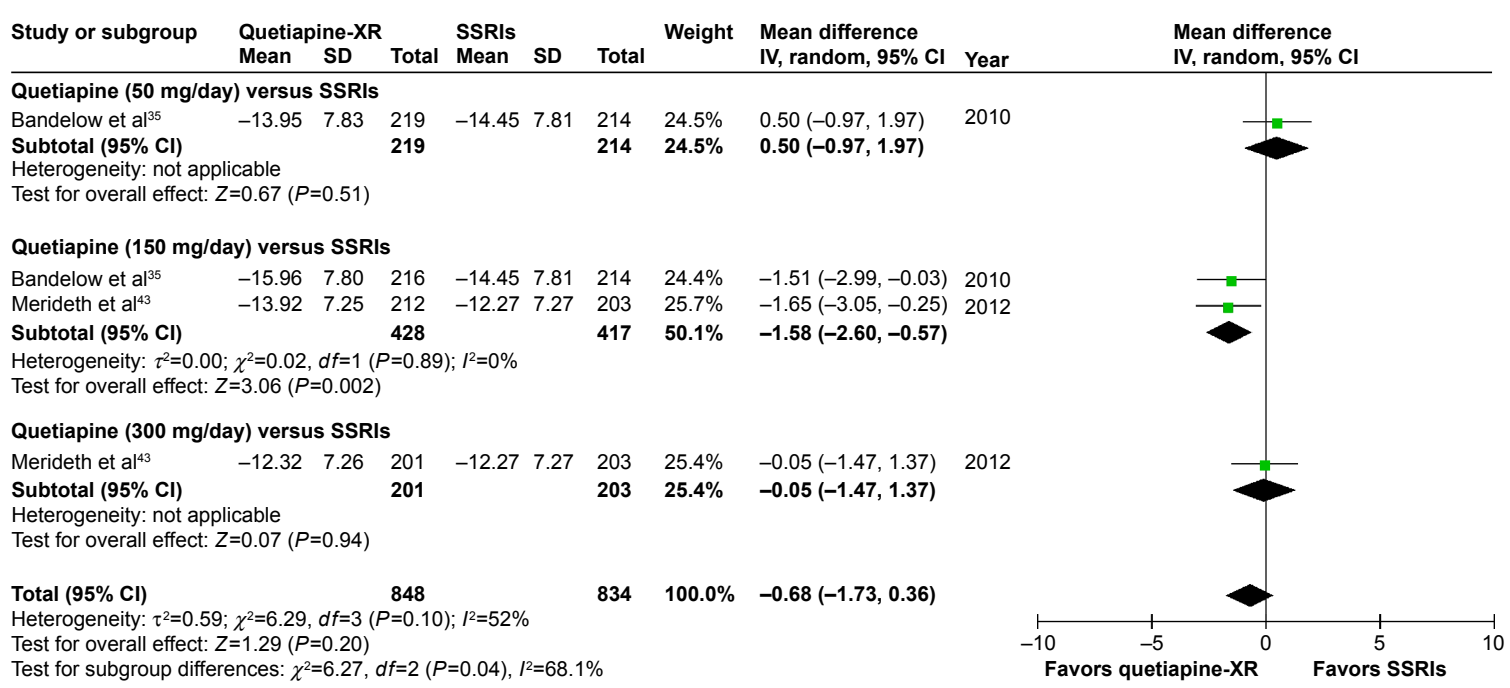

Figure 7 The forest plot of comparison of the mean changes from the baseline of the HAM-A scores (95\% confidence interval) of quetiapine vs SSRIs in GAD. Abbreviations: $\mathrm{Cl}$, confidence interval; IV, inverse variance; $d f$, degrees of freedom; GAD, generalized anxiety disorder; SD, standard deviation; $X R$, extended-release; HAM-A, Hamilton Anxiety Rating Scale; SSRIs, selective serotonin reuptake inhibitors.

of quetiapine is less than placebo in the treatment of GAD (Figure 16).

\section{Quetiapine versus SSRIs}

Significant heterogeneity was not observed in the overall discontinuation rate between quetiapine-treated and SSRIstreated groups. The pooled overall discontinuation rate of the quetiapine-treated group was significantly greater than that of the SSRIs-treated group, with RRs (95\% CI) of 1.23 $(1.05,1.44), I^{2}=0 \%$. Based on subgroup analysis of the overall discontinuation rate, only quetiapine at 50 and $150 \mathrm{mg} /$ day was comparable to SSRIs (Figure 17).

\section{Discontinuation rate due to adverse events (tolerability)} Quetiapine versus placebo

Significant heterogeneity was not observed in the discontinuation rate due to adverse events between quetiapine-treated and placebo-treated groups. Based on the pooled discontinuation rate due to adverse events of the quetiapine-treated group

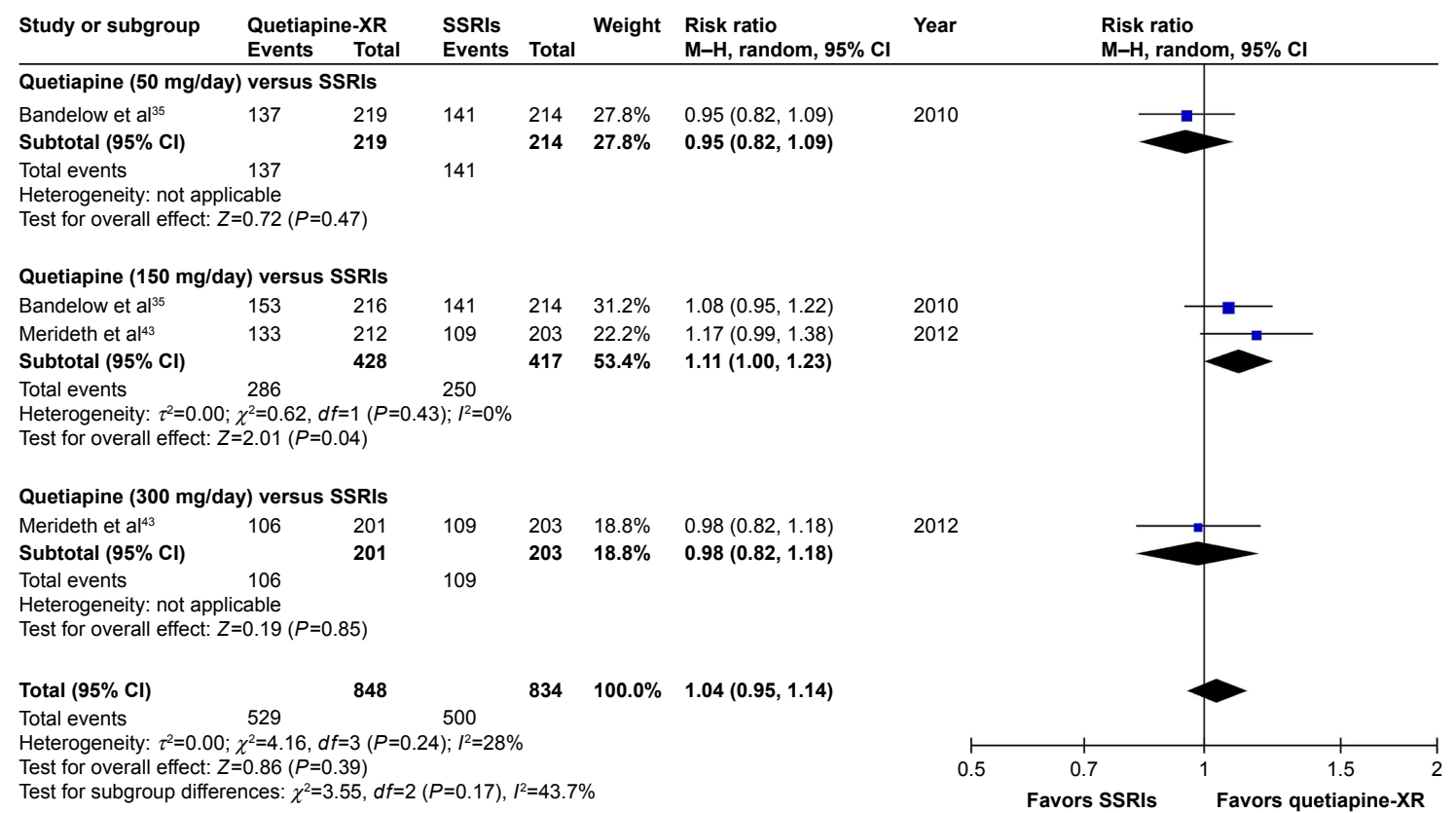

Figure 8 The forest plot of comparison of relative risks ( $95 \%$ confidence interval) for the clinical response rates of quetiapine vs SSRIs in GAD.

Abbreviations: $\mathrm{Cl}$, confidence interval; $d f$, degrees of freedom; GAD, generalized anxiety disorder; $\mathrm{M}-\mathrm{H}$, Mantel-Haenszel; XR, extended-release; SSRIs, selective serotonin reuptake inhibitors. 


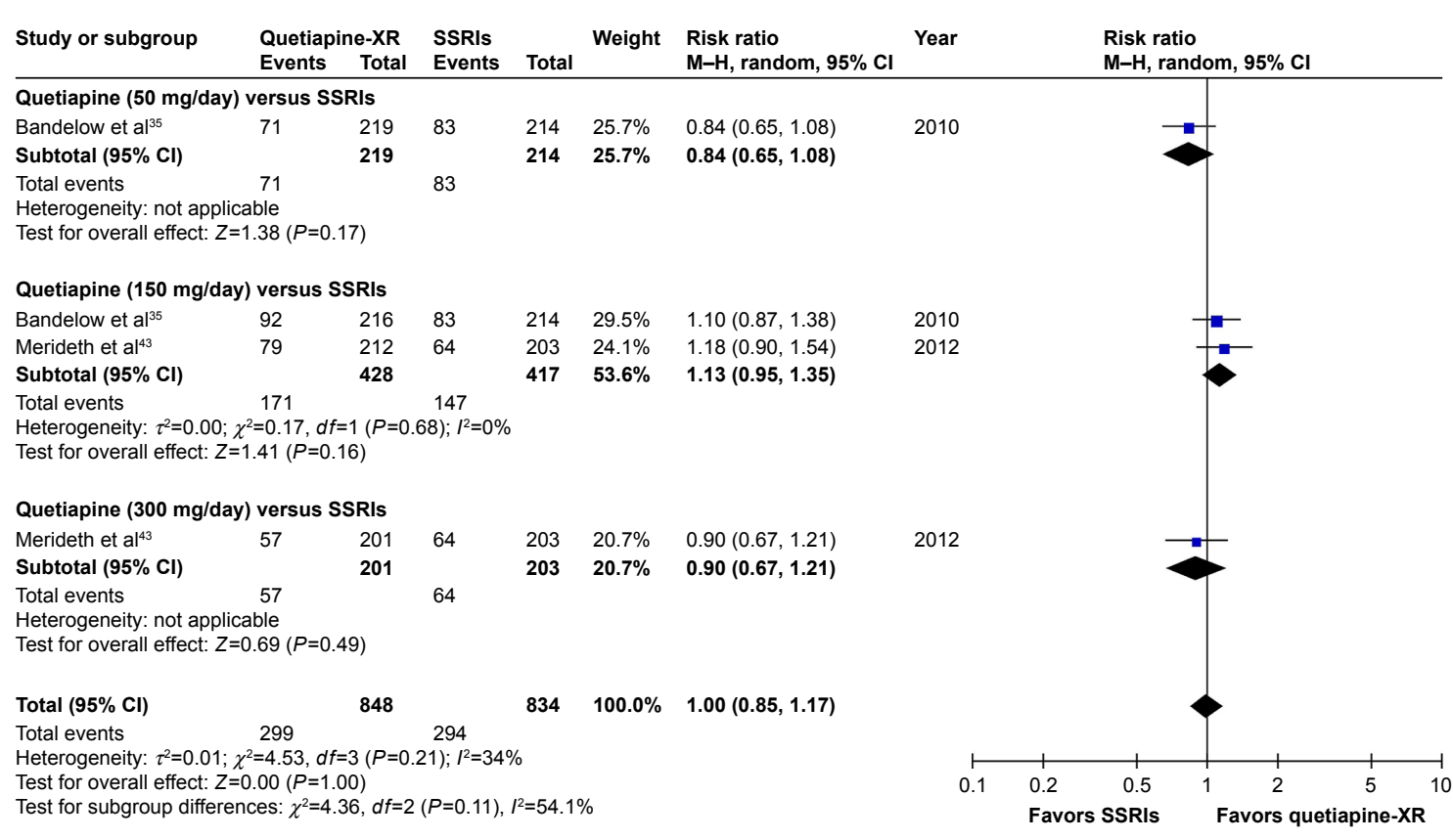

Figure 9 The forest plot of comparison of relative risks ( $95 \%$ confidence interval) for the clinical remission rates of quetiapine vs SSRIs in GAD.

Abbreviations: $\mathrm{Cl}$, confidence interval; $d f$, degrees of freedom; GAD, generalized anxiety disorder; $\mathrm{M}-\mathrm{H}$, Mantel-Haenszel; XR, extended-release; SSRIs, selective serotonin reuptake inhibitors.

being significantly higher than that of the placebo-treated group, with RR $\left(95 \%\right.$ CI) of $3.18(2.52,4.00), l^{2}=0 \%$, it suggests that quetiapine is less tolerable than placebo in the treatment of GAD (Figure 18).

\section{Quetiapine versus SSRIs}

Significant heterogeneity was not noted in the discontinuation rate due to adverse events between quetiapine-treated and SSRIs-treated groups. The pooled discontinuation rate due to adverse events of the quetiapine-treated group was significantly higher than that of the placebo-treated group, with RR $(95 \% \mathrm{CI})$ of $2.07(1.58,2.71), I^{2}=0 \%$. Considered in subgroup analysis of the discontinuation rate due to adverse events, only a tolerability of quetiapine at $50 \mathrm{mg} /$ day was comparable to SSRIs (Figure 19).

\section{Risk of bias across studies}

In the case of a systematic review and meta-analysis which includes the clinical studies of less than ten trials, a funnel plot which examines the publication bias may not have

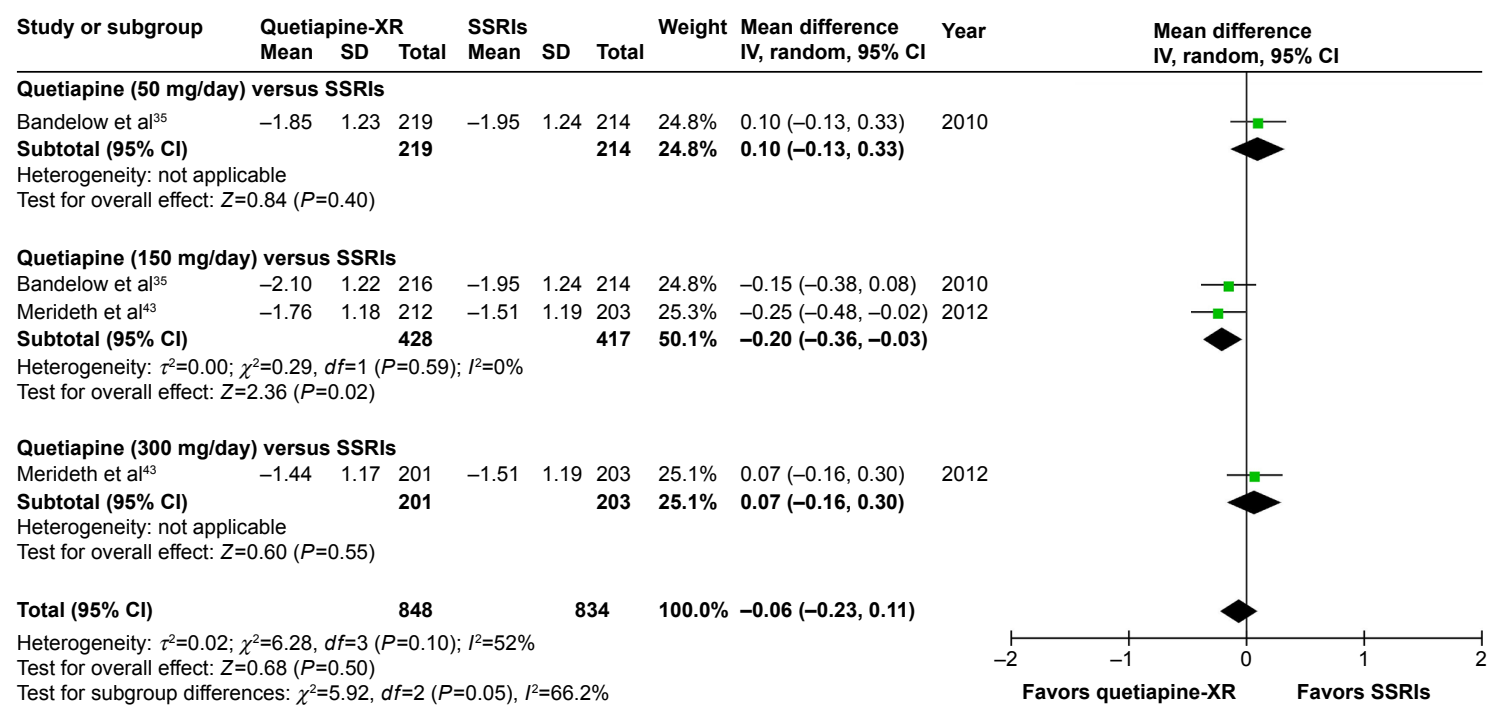

Figure 10 The forest plot of comparison of the mean changes from the baseline of the CGI-S scores (95\% confidence interval) of quetiapine vs SSRIs in GAD. Abbreviations: $\mathrm{Cl}$, confidence interval; IV, inverse variance; $d f$, degrees of freedom; GAD, generalized anxiety disorder; SD, standard deviation; CGI-S, Clinical Global Impression-Severity; XR, extended-release; SSRIs, selective serotonin reuptake inhibitors. 


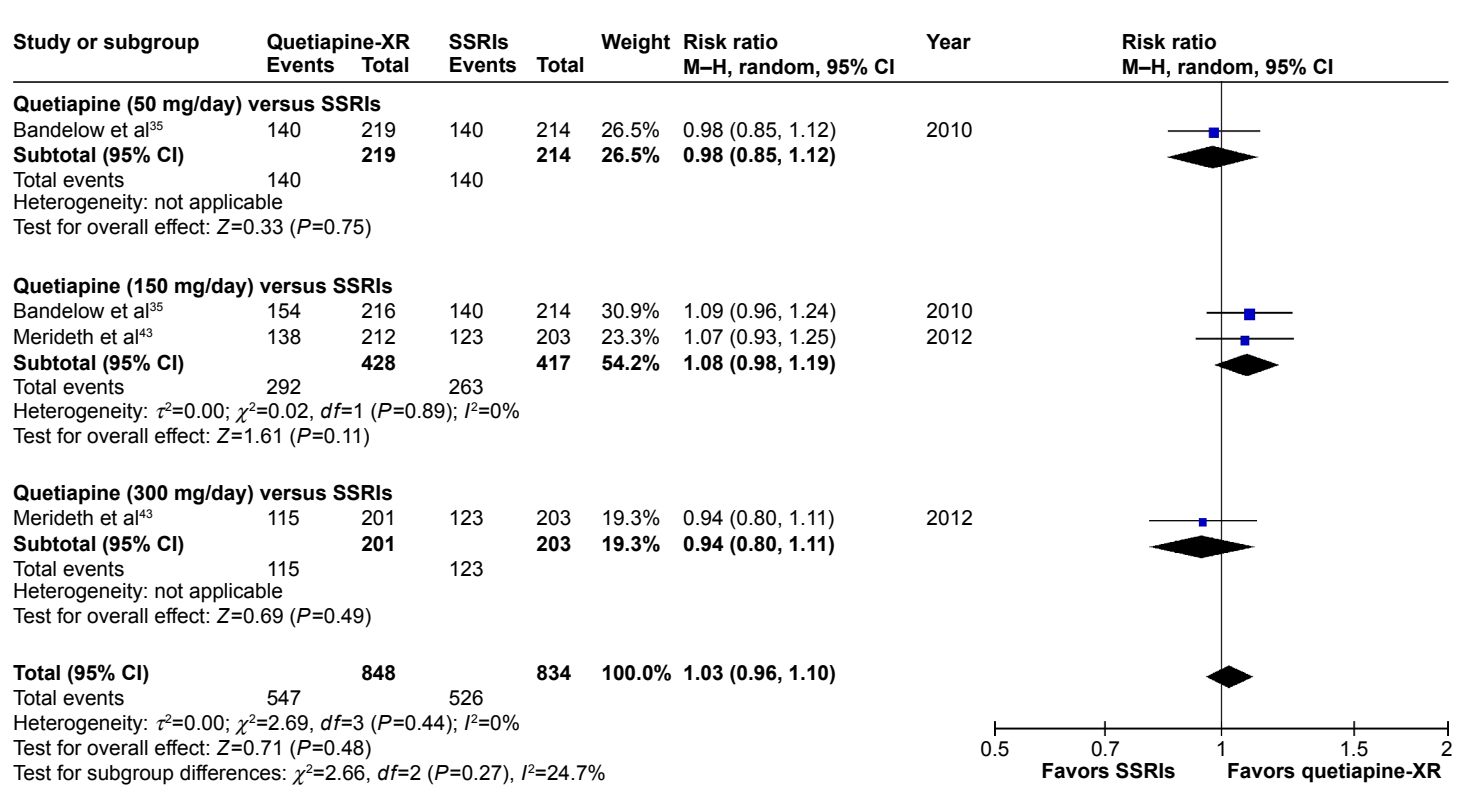

Figure I I The forest plot of comparison of relative risks (95\% confidence interval) for the clinical improvement rate (CGI-I=I, 2) of quetiapine vs SSRIs in GAD. Abbreviations: $\mathrm{Cl}$, confidence interval; $d f$, degrees of freedom; GAD, generalized anxiety disorder; M-H, Mantel-Haenszel; CGI-I, Clinical Global Impression-Improvement; $X R$, extended-release; SSRIs, selective serotonin reuptake inhibitors.

enough power to verify the chances of real asymmetry occurring because of the included results. ${ }^{53}$ For that reason, the test of funnel plot was not conducted because this meta-analysis included only three RCTs.

\section{Discussion}

Based on the results obtained in this meta-analysis, it can be concluded that the findings suggest that 50 and $150 \mathrm{mg}$ /day of quetiapine-XR is effective in the treatment of adult GAD.
Based on the response rate, its number needed to treat of nine indicates that one in every nine patients with GAD will benefit from treatment with quetiapine. The PSQI scores obtained indicate that quetiapine treatment can improve the quality of sleep in patients with GAD. However, its acceptability was less than placebo. Only acceptability of quetiapine 50 and $150 \mathrm{mg} /$ day was comparable to SSRIs. Similarly, tolerability of quetiapine was less than placebo. Only tolerability of quetiapine $50 \mathrm{mg} /$ day was comparable to SSRIs.

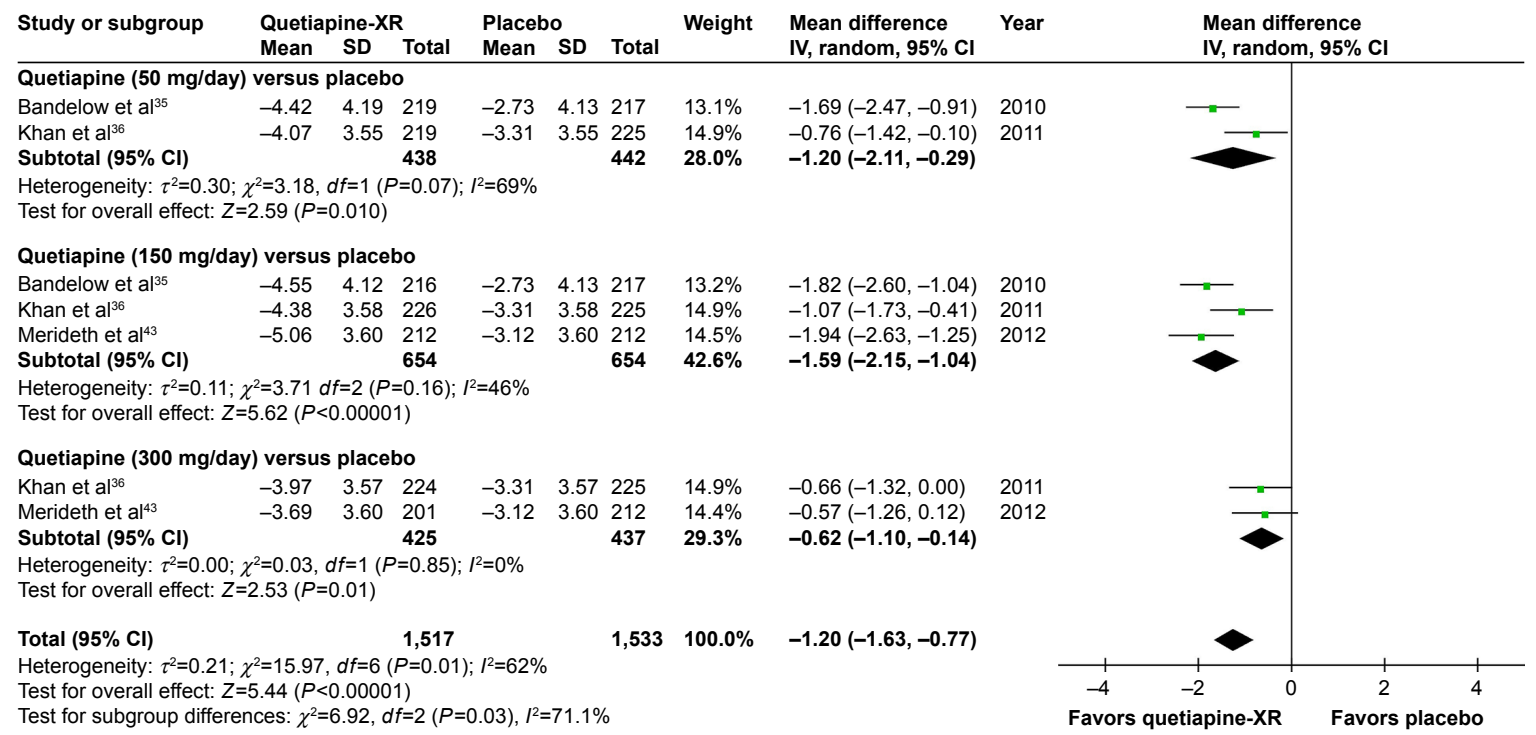

Figure 12 The forest plot of comparison of the mean changes from the baseline of the PSQI scores (95\% confidence interval) of quetiapine vs placebo in GAD. Abbreviations: $\mathrm{Cl}$, confidence interval; IV, inverse variance; $d$, degrees of freedom; GAD, generalized anxiety disorder; SD, standard deviation; XR, extended-release; PSQI, Pittsburgh Sleep Quality Index. 


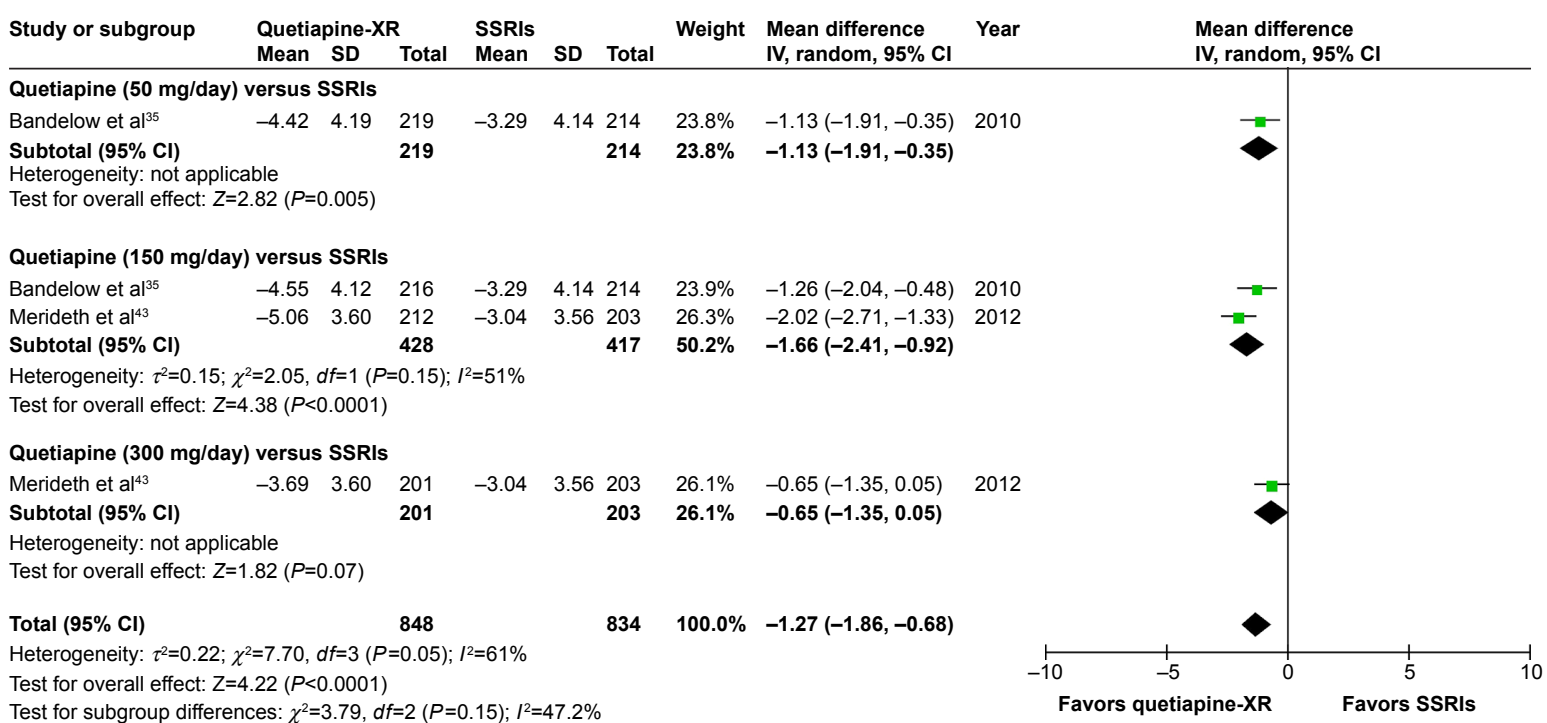

Figure 13 The forest plot of comparison of the mean changes from the baseline of the PSQI scores ( $95 \%$ confidence interval) of quetiapine vs SSRIs in GAD. Abbreviations: $\mathrm{Cl}$, confidence interval; IV, inverse variance; $d f$, degrees of freedom; GAD, generalized anxiety disorder; SD, standard deviation; XR, extended-release; PSQI, Pittsburgh Sleep Quality Index; SSRIs, selective serotonin reuptake inhibitors.

This meta-analysis suggests that low dose of quetiapine as well as SSRIs are efficacious in the treatment of adult patients with GAD which was similar to previous studies in the treatment of GAD with antidepressants, such as SSRIs and the SNRIs. ${ }^{11,22,63,64}$ Based on the response rate defined as a $\geq 50 \%$ reduction from the baseline in the HAM-A total score at endpoint, the response rates of quetiapine and SSRIs in this meta-analysis were $62.4 \%$ and $60.0 \%$, respectively, while the rate of response for duloxetine ${ }^{22}$ for GAD treatment in the previous study was $40 \%$. Considering the remission rate which is defined as a HAM-A total score of $\leq 7$ at endpoint, the remission rates of quetiapine and SSRIs in this metaanalysis were $35.3 \%$, equally, while the rates of remission for paroxetine ${ }^{8}$ and duloxetine ${ }^{22}$ in GAD treatment based on previous evidence were $28 \%$ and $30 \%-36 \%$, respectively.

One of the common symptoms of GAD is sleep disturbance. ${ }^{65}$ The incidence of sleep disturbance is often reported in SSRIs, except escitalopram. ${ }^{66}$ Although other antidepressants such as mirtazapine has a sleep-promoting effect in major depressive disorder ${ }^{67}$ its efficacy in the treatment of

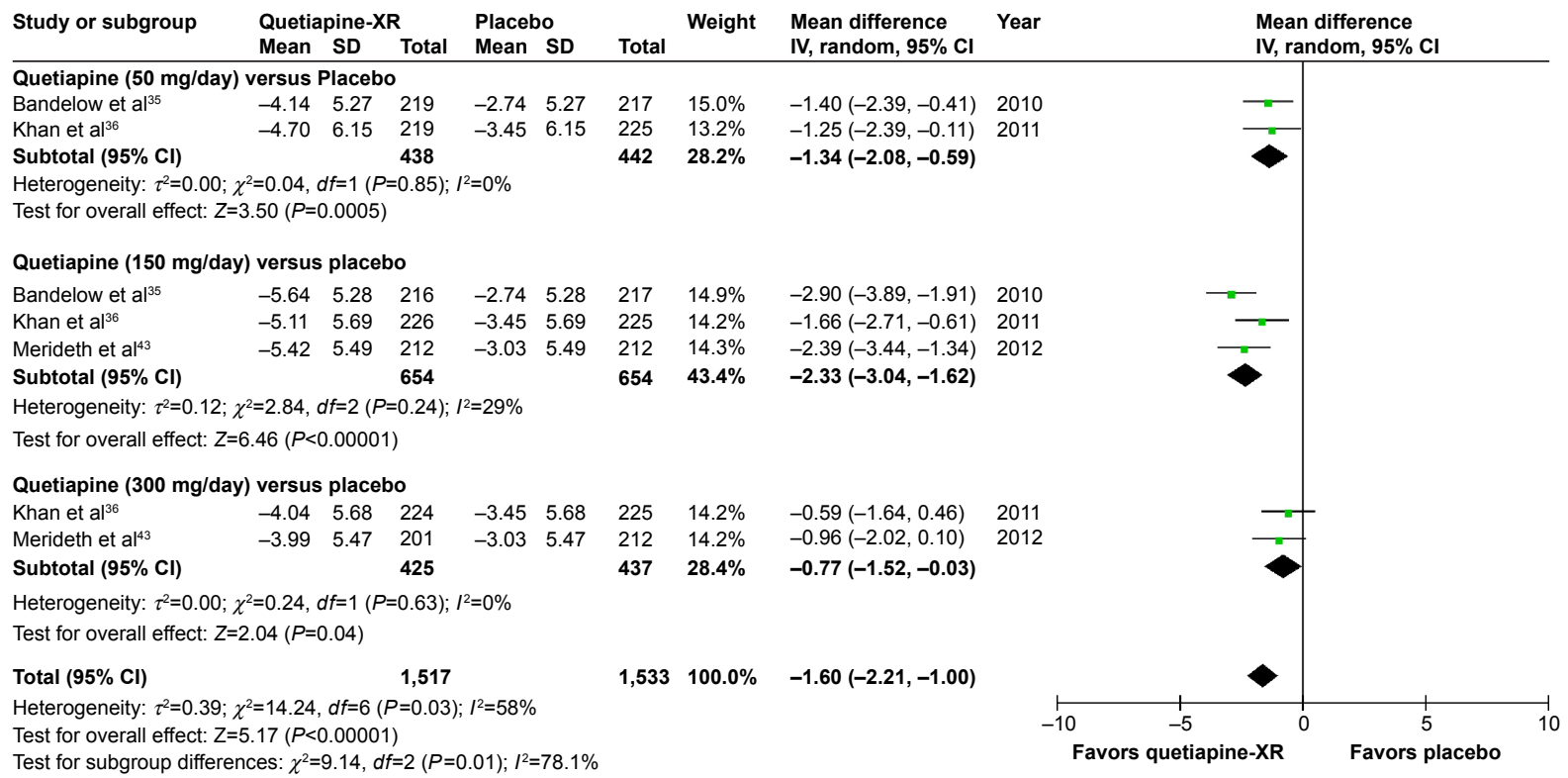

Figure 14 The forest plot of comparison of the mean changes from the baseline of the MADRS scores (95\% confidence interval) of quetiapine vs placebo in GAD. Abbreviations: $\mathrm{Cl}$, confidence interval; IV, inverse variance; $d f$, degrees of freedom; GAD, generalized anxiety disorder; MADRS, Montgomery-Åsberg Depression Rating Scale; SD, standard deviation; $X R$, extended-release. 


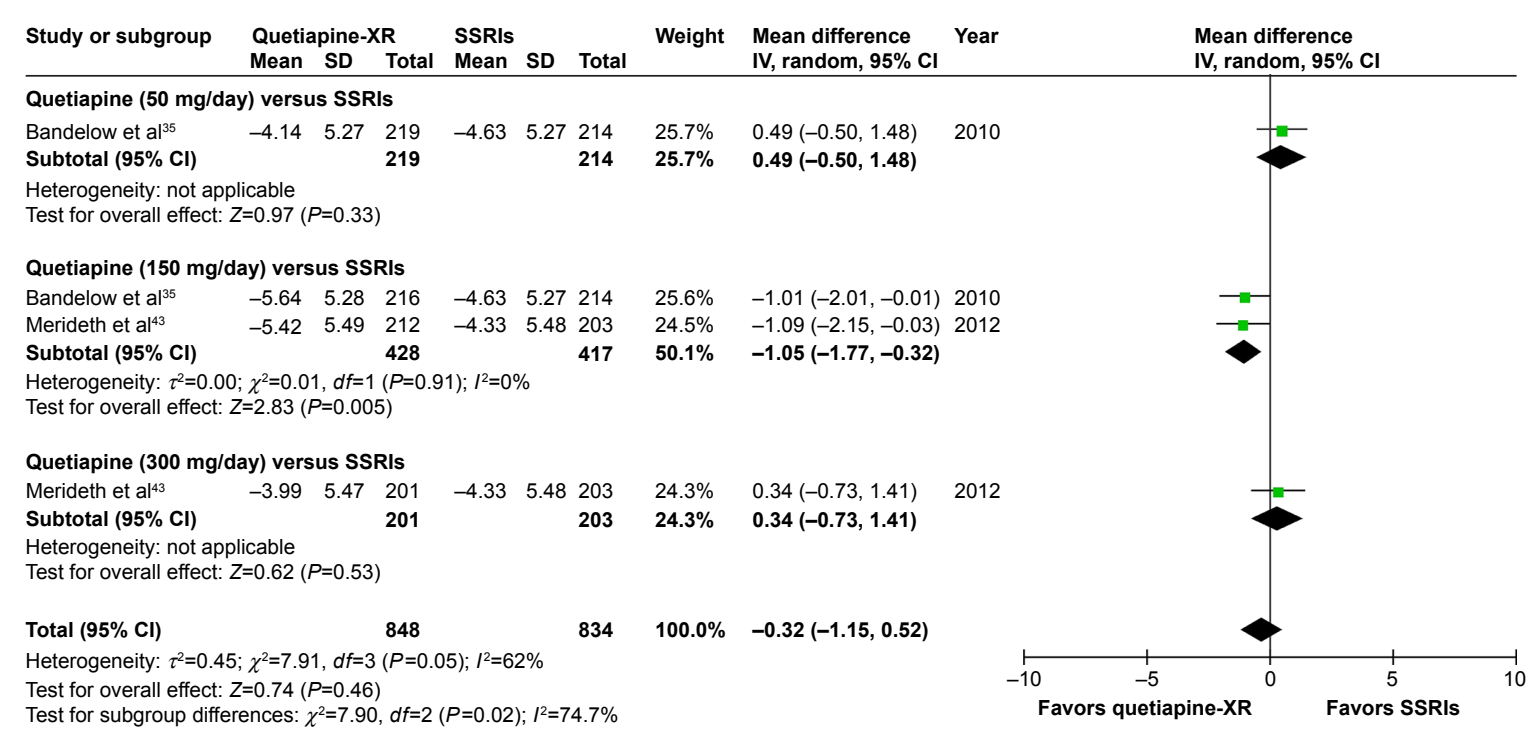

Figure 15 The forest plot of comparison of the mean changes from the baseline of the MADRS scores (95\% confidence interval) of quetiapine vs SSRIs in GAD. Abbreviations: $\mathrm{Cl}$, confidence interval; IV, inverse variance; df, degrees of freedom; GAD, generalized anxiety disorder; MADRS, Montgomery-Åsberg Depression Rating Scale; SD, standard deviation; XR, extended-release; SSRIs, selective serotonin reuptake inhibitors.

GAD patients needs more studies to confirm this. This sleep disturbance may lead those patients to the requirement of additional sedative drugs such as benzodiazepine, having the potential risk of intolerance, possible drug abuse and dependence, for alleviating this symptom. ${ }^{22,68}$ Based on findings in the present meta-analysis, quetiapine may have an effective role in the treatment of such patients because of its better sleep promoting quality compared to SSRIs. Although quetiapine can promote sleep quality, its sedative effect may negatively impact daytime functioning. Hence, administration of quetiapine-XR in the evening may avoid this adverse event.

In this meta-analysis, the acceptability of quetiapine at all doses in GAD treatment was less than that of the placebo. However, acceptability of quetiapine at 50 and $150 \mathrm{mg} /$ day,

\begin{tabular}{|c|c|c|c|c|c|c|c|c|c|c|c|}
\hline \multirow{2}{*}{\multicolumn{3}{|c|}{\begin{tabular}{lc} 
Study or subgroup & \multicolumn{2}{c}{ Quetiapine } \\
Events Total
\end{tabular}}} & \multirow[t]{2}{*}{$\begin{array}{l}\text { Placebo } \\
\text { Events }\end{array}$} & \multirow[t]{2}{*}{ Total } & \multirow[t]{2}{*}{ Weight } & \multirow[t]{2}{*}{$\begin{array}{l}\text { Risk ratio } \\
\mathrm{M}-\mathrm{H} \text {, random, } 95 \% \mathrm{Cl}\end{array}$} & \multicolumn{2}{|l|}{ Year } & \multicolumn{3}{|c|}{$\begin{array}{l}\text { Risk ratio } \\
\mathrm{M}-\mathrm{H} \text {, random, } 95 \% \mathrm{CI}\end{array}$} \\
\hline & & & & & & & & & & & \\
\hline Bandelow et al ${ }^{35}$ & 57 & 221 & 41 & 217 & $10.9 \%$ & $1.37(0.96,1.95)$ & 2010 & & & & \\
\hline Khan et $\mathrm{al}^{36}$ & 72 & 234 & 70 & 235 & $16.1 \%$ & $1.03(0.78,1.36)$ & 2011 & & & & \\
\hline Subtotal $(95 \% \mathrm{Cl})$ & & 455 & & 452 & $27.0 \%$ & $1.16(0.89,1.52)$ & & & & & \\
\hline \multicolumn{12}{|c|}{$\begin{array}{l}\text { Heterogeneity: } \tau^{2}=0.01 ; \chi^{2}=1.49, d f=1(P=0.22) ; l^{2}=33 \% \\
\text { Test for overall effect: } Z=1.08(P=0.28)\end{array}$} \\
\hline \multicolumn{12}{|c|}{ Quetiapine (150 mg/day) versus Placebo } \\
\hline Bandelow et al ${ }^{35}$ & 55 & 218 & 41 & 217 & $10.8 \%$ & $1.34(0.93,1.91)$ & 2010 & & & & \\
\hline Khan et al ${ }^{36}$ & 87 & 241 & 70 & 235 & $17.5 \%$ & $1.21(0.94,1.57)$ & 2011 & & & & \\
\hline Merideth et al ${ }^{43}$ & 63 & 219 & 46 & 215 & $12.3 \%$ & $1.34(0.97,1.87)$ & 2012 & & & & \\
\hline Subtotal $(95 \% \mathrm{Cl})$ & & 678 & & 667 & $40.6 \%$ & $1.28(1.07,1.53)$ & & & & & \\
\hline Total events & 205 & & 157 & & & & & & & & \\
\hline \multicolumn{12}{|c|}{$\begin{array}{l}\text { Heterogeneity: } \tau^{2}=0.00 ; \chi^{2}=0.31, d f=2(P=0.86) ; I^{2}=0 \% \\
\text { Test for overall effect: } Z=2.72(P=0.006)\end{array}$} \\
\hline \multicolumn{12}{|c|}{ Quetiapine (300 mg/day) versus Placebo } \\
\hline Khan et al ${ }^{36}$ & 102 & 241 & 70 & 235 & $18.7 \%$ & $1.42(1.11,1.82)$ & 2011 & & & 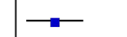 & \\
\hline Merideth et $\mathrm{al}^{43}$ & 81 & 207 & 46 & 215 & $13.7 \%$ & $1.83(1.34,2.49)$ & 2012 & & & & \\
\hline Subtotal $(95 \% \mathrm{Cl})$ & & 448 & & 450 & $32.4 \%$ & $1.58(1.24,2.02)$ & & & & & \\
\hline Total events & 183 & & 116 & & & & & & & & \\
\hline \multicolumn{12}{|c|}{$\begin{array}{l}\text { Heterogeneity: } \tau^{2}=0.01 ; \chi^{2}=1.59, d f=1(P=0.21) ; I^{2}=37 \% \\
\text { Test for overall effect: } Z=3.67(P=0.0002)\end{array}$} \\
\hline Total $(95 \% \mathrm{Cl})$ & & 1,581 & & 1,569 & $100.0 \%$ & $1.33(1.17,1.52)$ & & & & & \\
\hline Total events & 517 & & 384 & & & & & & & & \\
\hline \multicolumn{7}{|c|}{ Heterogeneity: $\tau^{2}=0.01 ; \chi^{2}=8.18, d f=6(P=0.23) ; I^{2}=27 \%$} & $\stackrel{\longmapsto}{0.1}$ & 0.2 & 0.5 & $\frac{1}{2}$ & $\frac{1}{5}$ \\
\hline \multicolumn{7}{|c|}{$\begin{array}{l}\text { Test for overall effect: } Z=4.30(P<0.0001) \\
\text { Test for subgroup differences: } \chi^{2}=3.12, d f=2(P=0.21) ; I^{2}=35.9 \%\end{array}$} & \multicolumn{3}{|c|}{ Favors quetiapine-XR } & Favors & Icebo \\
\hline
\end{tabular}

Figure 16 The forest plot of comparison of relative risks ( $95 \%$ confidence interval) for the overall discontinuation rate of quetiapine vs placebo in GAD. Abbreviations: $\mathrm{Cl}$, confidence interval; $d f$, degrees of freedom; GAD, generalized anxiety disorder; $M-H$, Mantel-Haenszel; XR, extended-release. 


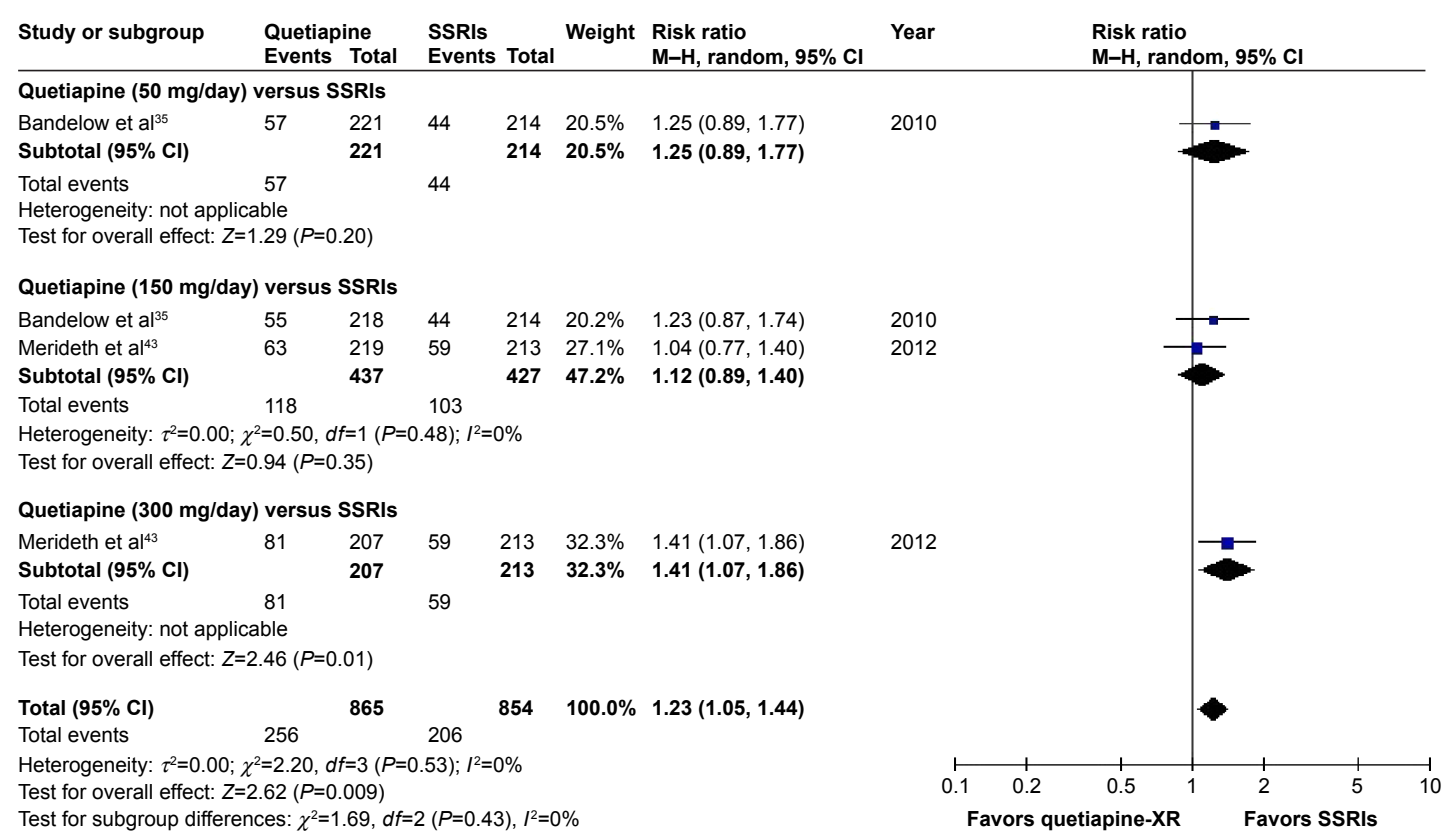

Figure 17 The forest plot of comparison of relative risks (95\% confidence interval) for the overall discontinuation rate of quetiapine vs SSRIs in GAD.

Abbreviations: $\mathrm{Cl}$, confidence interval; $d f$, degrees of freedom; GAD, generalized anxiety disorder; $M-H$, Mantel-Haenszel; XR, extended-release; SSRIs, selective serotonin reuptake inhibitors.

but not for quetiapine at $300 \mathrm{mg} / \mathrm{day}$, was comparable to SSRIs. Similarly, the tolerability of quetiapine at all doses in GAD treatment was found to be less than that of the placebo which is comparable with antidepressants, including SSRIs and SNRIs in the treatment of GAD patients. ${ }^{4,11,20}$ Unfortunately, only tolerability of low dose quetiapine in the present meta-analysis was comparable to SSRIs. The relative low acceptability and tolerability of higher dose quetiapine may be caused by its adverse events. Based on the evidence included in this meta-analysis, the significant adverse events consist of somnolence, sexual dysfunction, and extrapyramidal symptoms. ${ }^{35,36,43}$ Hence, the use of

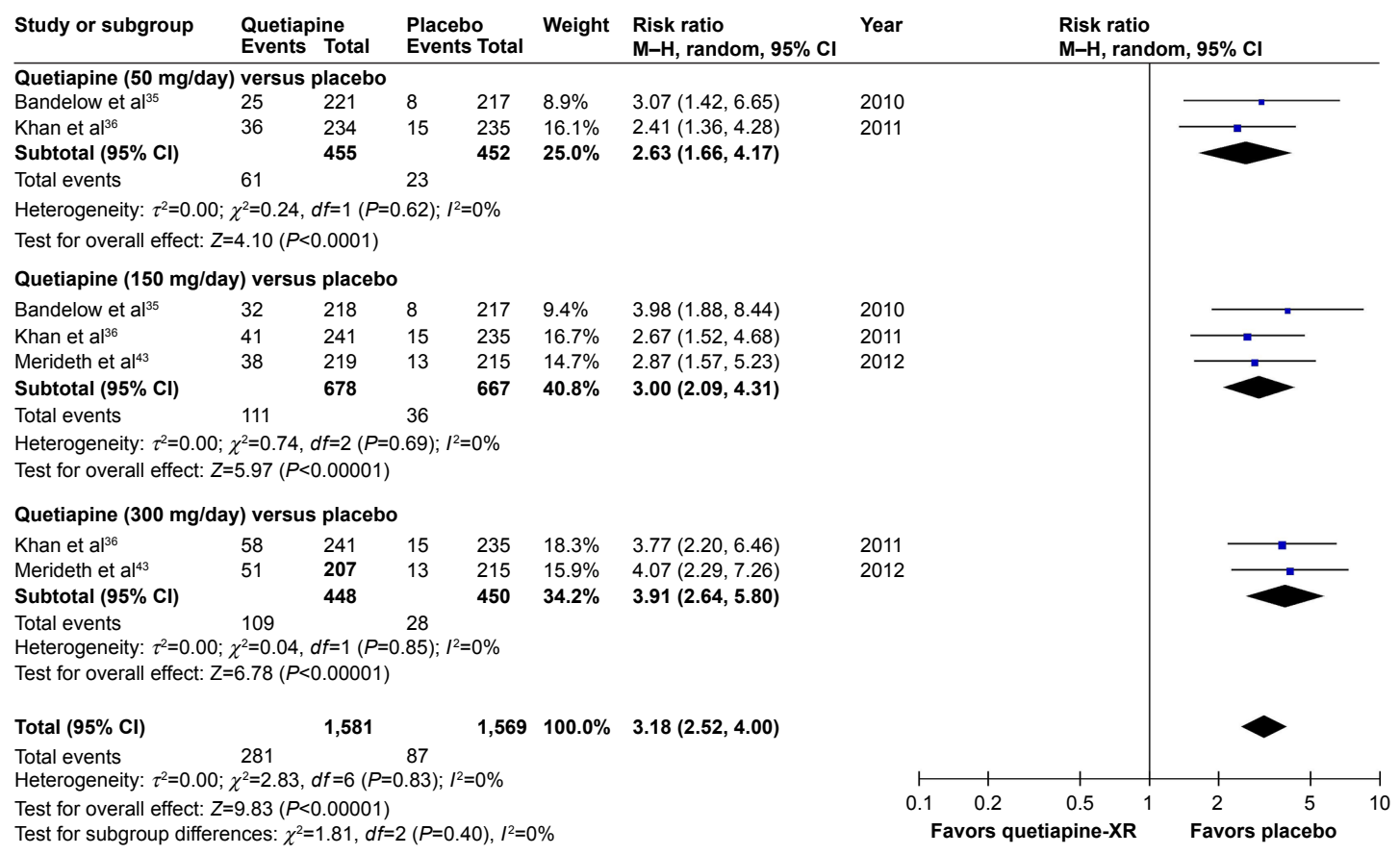

Figure 18 The forest plot of comparison of relative risks ( $95 \%$ confidence interval) for the discontinuation rate due to adverse events of quetiapine vs placebo in GAD. Abbreviations: $\mathrm{Cl}$, confidence interval; $d f$, degrees of freedom; GAD, generalized anxiety disorder; $M-H$, Mantel-Haenszel; XR, extended-release. 


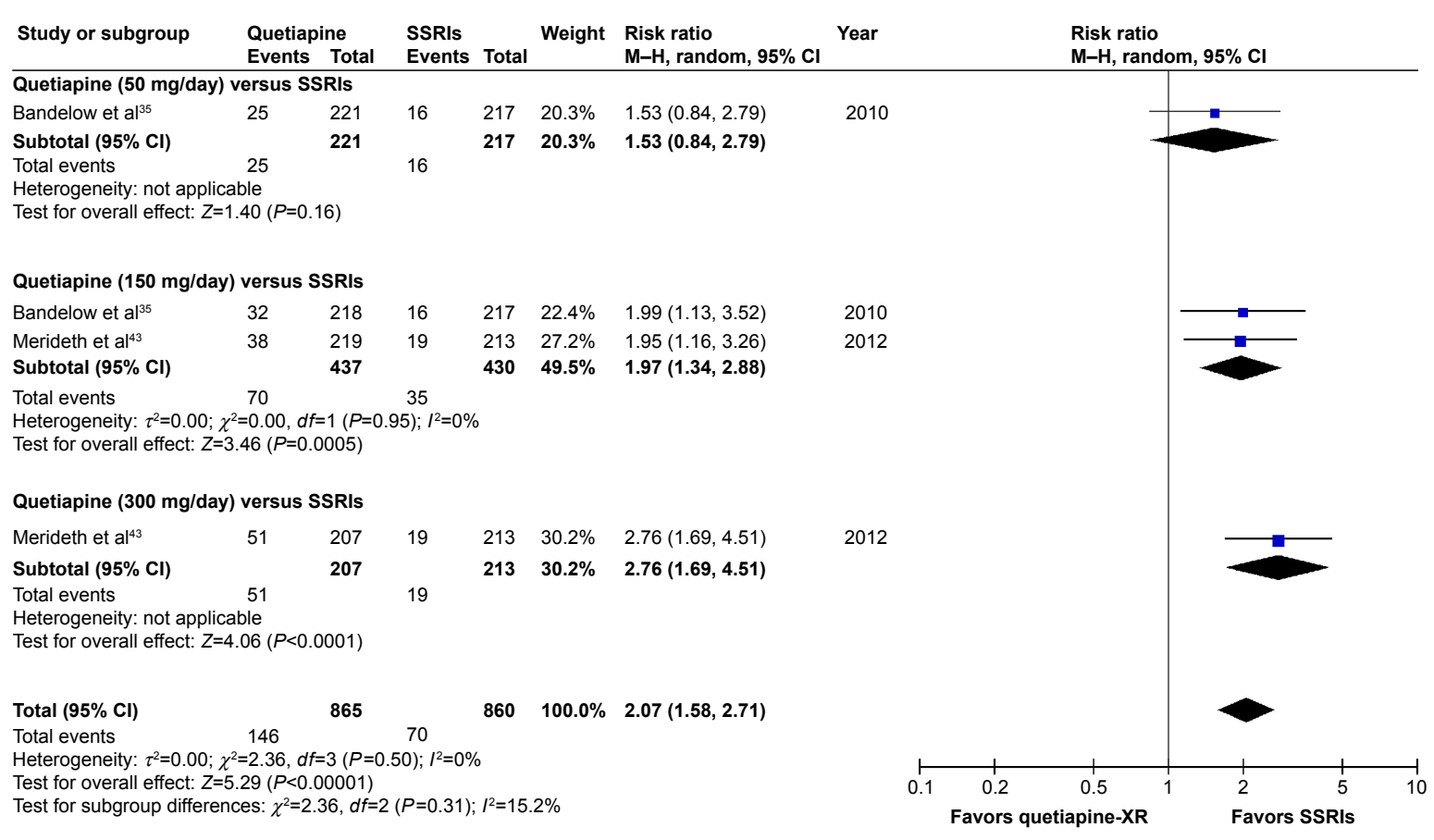

Figure 19 The forest plot of comparison of relative risks (95\% confidence interval) for the discontinuation rate due to adverse events of quetiapine vs SSRIs in GAD. Abbreviations: $\mathrm{Cl}$, confidence interval; $d f$, degrees of freedom; GAD, generalized anxiety disorder; $\mathrm{M}-\mathrm{H}$, Mantel-Haenszel; SSRIs, selective serotonin reuptake inhibitors.

quetiapine in such patients should be cautiously monitored for the occurrence of any adverse events.

\section{Limitations}

This meta-analysis had some limitations. First, there were only three RCTs included in this meta-analysis, which affected the number of the sample size. Second, the included clinical studies were funded by a patent holding company for quetiapine-XR. Hence, further independent clinical studies, even if open-label, could determine its benefit in GAD patients. Third, since two of three included studies were carried out in the USA, the outcomes may not be representative for other populations. Therefore, caution should be exercised in terms of generalization of those findings. Finally, some potential bias issues (detection and reporting biases) of two included trials ${ }^{36,43}$ were unclear. Additionally, the test of funnel plot to examine asymmetry could not be conducted since the number of included RCTs was small. ${ }^{53}$ Hence, in this meta-analysis, publication bias cannot be excluded.

\section{Conclusion}

Based on the limited evidences from this meta-analysis, it can be concluded that low dose quetiapine-XR (50-150 mg/day) is efficacious in the treatment of GAD in adult patients. Additionally, its sedative effects may improve the sleep quality of such patients. Unfortunately, its acceptability and tolerability were found to be less than those of the placebo. However, the acceptability and tolerability of low dose quetiapine were comparable to SSRIs. According to the present meta-analysis, the use of quetiapine in low dose ( $50-150 \mathrm{mg} /$ day) for adult GAD patients may be considered as an alternative treatment. Although low dose quetiapine appears to be effective and tolerable in the treatment of GAD patients, use of this active agent in clinical practice should be cautiously carried out because of adverse events. Further well-defined studies should be conducted to warrant these outcomes.

\section{Acknowledgments}

Narong Maneeton and Benchalak Maneeton share first authorship. This meta-analysis received financial support from Chiang Mai University, Thailand.

\section{Author contributions}

All authors contributed toward data analysis, drafting and revising the paper and agree to be accountable for all aspects of the work.

\section{Disclosure}

NM has received travel reimbursement from Lundbeck and Pfizer. BM has received honoraria and/or travel reimbursement from Lundbeck and Pfizer. PW has no potential conflict of interest. SL has received honoraria and/or travel reimbursement from Janssen-Cilag, Lundbeck, Daiichi Sankyo, and Pfizer. SS has received honoraria and/or research grants 
from Janssen-Cilag, Thai-Otsuka, Lundbeck, and AstraZeneca. VB has no potential conflict of interest. MS has received honoraria, consultancy fees, research grants, and/or travel reimbursement from AstraZeneca, GlaxoSmithKline, Pfizer, Janssen-Cilag, Johnson \& Johnson, Lundbeck, Thai-Otsuka, Sanofi-Aventis, and Servier.

\section{References}

1. Tyrer P, Baldwin D. Generalised anxiety disorder. Lancet. 2006; 368(9553):2156-2166.

2. Cuijpers P, Sijbrandij M, Koole S, Huibers M, Berking M, Andersson G. Psychological treatment of generalized anxiety disorder: a metaanalysis. Clin Psychol Rev. 2014;34(2):130-140.

3. Szkodny LE, Newman MG, Goldfried MR. Clinical experiences in conducting empirically supported treatments for generalized anxiety disorder. Behav Ther. 2014;45(1):7-20.

4. Schmitt R, Gazalle FK, Lima MS, Cunha A, Souza J, Kapczinski F. The efficacy of antidepressants for generalized anxiety disorder: a systematic review and meta-analysis. Rev Bras Psiquiatr. 2005;27(1):18-24 .

5. Kapczinski F, Lima MS, Souza JS, Schmitt R. Antidepressants for generalized anxiety disorder. Cochrane Database Syst Rev. 2003;(2): CD003592.

6. Pollack MH, Zaninelli R, Goddard A, et al. Paroxetine in the treatment of generalized anxiety disorder: results of a placebo-controlled, flexibledosage trial. J Clin Psychiatry. 2001;62(5):350-357.

7. Liebowitz MR, Stein MB, Tancer M, Carpenter D, Oakes R, Pitts CD. A randomized, double-blind, fixed-dose comparison of paroxetine and placebo in the treatment of generalized social anxiety disorder. $J$ Clin Psychiatry. 2002;63(1):66-74.

8. Rickels K, Zaninelli R, McCafferty J, Bellew K, Iyengar M, Sheehan D. Paroxetine treatment of generalized anxiety disorder: a double-blind, placebo-controlled study. Am J Psychiatry. 2003;160(4):749-756.

9. Stocchi F, Nordera G, Jokinen RH, et al. Efficacy and tolerability of paroxetine for the long-term treatment of generalized anxiety disorder. J Clin Psychiatry. 2003;64(3):250-258.

10. Allgulander C, Dahl AA, Austin C, et al. Efficacy of sertraline in a 12-week trial for generalized anxiety disorder. Am J Psychiatry. 2004; 161(9):1642-1649.

11. Brawman-Mintzer O, Knapp RG, Rynn M, Carter RE, Rickels K. Sertraline treatment for generalized anxiety disorder: a randomized, double-blind, placebo-controlled study. J Clin Psychiatry. 2006;67(6):874-881.

12. Varia I, Rauscher F. Treatment of generalized anxiety disorder with citalopram. Int Clin Psychopharmacol. 2002;17(3):103-107.

13. Davidson JR, Bose A, Korotzer A, Zheng H. Escitalopram in the treatment of generalized anxiety disorder: double-blind, placebo controlled, flexible-dose study. Depress Anxiety. 2004;19(4):234-240.

14. Davidson JR, Bose A, Wang Q. Safety and efficacy of escitalopram in the long-term treatment of generalized anxiety disorder. J Clin Psychiatry. 2005;66(11):1441-1446.

15. Katz IR, Reynolds CF 3rd, Alexopoulos GS, Hackett D. Venlafaxine ER as a treatment for generalized anxiety disorder in older adults: pooled analysis of five randomized placebo-controlled clinical trials. $\mathrm{J} \mathrm{Am}$ Geriatr Soc. 2002;50(1):18-25.

16. Wright A, Vandenberg C. Duloxetine in the treatment of generalized anxiety disorder. Int J Gen Med. 2009;2:153-162.

17. Bystritsky A, Kerwin L, Feusner JD, Vapnik T. A pilot controlled trial of bupropion XL versus escitalopram in generalized anxiety disorder. Psychopharmacol Bull. 2008;41(1):46-51.

18. Stein MB, Pollack MH, Bystritsky A, Kelsey JE, Mangano RM. Efficacy of low and higher dose extended-release venlafaxine in generalized social anxiety disorder: a 6-month randomized controlled trial. Psychopharmacology (Berl). 2005;177(3):280-288.

19. Koponen H, Allgulander C, Erickson J, et al. Efficacy of duloxetine for the treatment of generalized anxiety disorder: implications for primary care physicians. Prim Care Companion J Clin Psychiatry. 2007;9(2):100-107.
20. Bose A, Korotzer A, Gommoll C, Li D. Randomized placebo-controlled trial of escitalopram and venlafaxine XR in the treatment of generalized anxiety disorder. Depress Anxiety. 2008;25(10):854-861.

21. Allgulander C, Hackett D, Salinas E. Venlafaxine extended release (ER) in the treatment of generalised anxiety disorder: twenty-four-week placebocontrolled dose-ranging study. Br J Psychiatry. 2001;179:15-22.

22. Rynn M, Russell J, Erickson J, et al. Efficacy and safety of duloxetine in the treatment of generalized anxiety disorder: a flexible-dose, progressivetitration, placebo-controlled trial. Depress Anxiety. 2008;25(3): 182-189.

23. Feighner JP. Overview of antidepressants currently used to treat anxiety disorders. J Clin Psychiatry. 1999;60 Suppl 22:18-22.

24. Rickels K, Rynn M. Pharmacotherapy of generalized anxiety disorder. J Clin Psychiatry. 2002;63 Suppl 14:9-16.

25. Montgomery SA. Tolerability of serotonin norepinephrine reuptake inhibitor antidepressants. CNS Spectr. 2008;13(7 Suppl 11):27-33.

26. American Psychiatric Association. Diagnostic and Statistical Manual of Mental Disorders. 5th ed. Arlington, VA: American Psychiatric Publishing; 2013.

27. Monti JM, Monti D. Sleep disturbance in generalized anxiety disorder and its treatment. Sleep Med Rev. 2000;4(3):263-276.

28. Belleville G, Cousineau H, Levrier K, St-Pierre-Delorme ME, Marchand A. The impact of cognitive-behavior therapy for anxiety disorders on concomitant sleep disturbances: a meta-analysis. $J$ Anxiety Disord. 2010;24(4):379-386.

29. Tsypes A, Aldao A, Mennin DS. Emotion dysregulation and sleep difficulties in generalized anxiety disorder. J Anxiety Disord. 2013;27(2): 197-203.

30. Roerig JL. Diagnosis and management of generalized anxiety disorder. J Am Pharm Assoc (Wash). 1999;39(6):811-821.

31. Canadian Agency for Drugs and Technologies in Health. Short- and Long-Term Use of Benzodiazepines in Patients with Generalized Anxiety Disorder: A Review of Guidelines. Ottawa (ON): Canadian Agency for Drugs and Technologies in Health; 2014.

32. Wilson S, Argyropoulos S. Antidepressants and sleep: a qualitative review of the literature. Drugs. 2005;65(7):927-947.

33. DeVane CL, Nemeroff CB. Clinical pharmacokinetics of quetiapine: an atypical antipsychotic. Clin Pharmacokinet. 2001;40(7):509-522.

34. Figueroa C, Brecher M, Hamer-Maansson JE, Winter H. Pharmacokinetic profiles of extended release quetiapine fumarate compared with quetiapine immediate release. Prog Neuropsychopharmacol Biol Psychiatry. 2009;33(2):199-204.

35. Bandelow B, Chouinard G, Bobes J, et al. Extended-release quetiapine fumarate (quetiapine XR): a once-daily monotherapy effective in generalized anxiety disorder. Data from a randomized, double-blind, placebo- and active-controlled study. Int J Neuropsychopharmacol. 2010; 13(3):305-320.

36. Khan A, Joyce M, Atkinson S, Eggens I, Baldytcheva I, Eriksson H. A randomized, double-blind study of once-daily extended release quetiapine fumarate (quetiapine XR) monotherapy in patients with generalized anxiety disorder. J Clin Psychopharmacol. 2011;31(4): 418-428.

37. Katzman MA, Brawman-Mintzer O, Reyes EB, Olausson B, Liu S, Eriksson H. Extended release quetiapine fumarate (quetiapine XR) monotherapy as maintenance treatment for generalized anxiety disorder: a long-term, randomized, placebo-controlled trial. Int Clin Psychopharmacol. 2011;26(1):11-24.

38. Horacek J, Bubenikova-Valesova V, Kopecek M, et al. Mechanism of action of atypical antipsychotic drugs and the neurobiology of schizophrenia. CNS Drugs. 2006;20(5):389-409.

39. Jensen NH, Rodriguiz RM, Caron MG, Wetsel WC, Rothman RB, Roth BL. N-desalkylquetiapine, a potent norepinephrine reuptake inhibitor and partial 5-HT1A agonist, as a putative mediator of quetiapine's antidepressant activity. Neuropsychopharmacology. 2008;33(10):2303-2312.

40. Bakken GV, Rudberg I, Molden E, Refsum H, Hermann M. Pharmacokinetic variability of quetiapine and the active metabolite N-desalkylquetiapine in psychiatric patients. Ther Drug Monit. 2011; 33(2):222-226. 
41. Goldstein JM, Nyberg S, Brecher M. Preclinical mechanisms for the broad spectrum of antipsychotic, antidepressant and mood stabilizing properties of Seroquel. European Psychiatry. 2008;23(Suppl 2):S202.

42. Maneeton N, Maneeton B, Srisurapanont M, Martin SD. Quetiapine monotherapy in acute phase for major depressive disorder: a metaanalysis of randomized, placebo-controlled trials. BMC Psychiatry. 2012;12:160.

43. Merideth C, Cutler AJ, She F, Eriksson H. Efficacy and tolerability of extended release quetiapine fumarate monotherapy in the acute treatment of generalized anxiety disorder: a randomized, placebo controlled and active-controlled study. Int Clin Psychopharmacol. 2012;27(1):40-54.

44. Srisurapanont M, Maneeton B, Maneeton N. Quetiapine for schizophrenia. Cochrane Database Syst Rev. 2004;(2):CD000967.

45. Maneeton B, Maneeton N, Srisurapanont M, Chittawatanarat K. Quetiapine versus haloperidol in the treatment of delirium: a double-blind, randomized, controlled trial. Drug Des Devel Ther. 2013;7:657-667.

46. Suttajit S, Srisurapanont M, Maneeton N, Maneeton B. Quetiapine for acute bipolar depression: a systematic review and meta-analysis. Drug Des Devel Ther. 2014;8:827-838.

47. Hamilton M. The assessment of anxiety states by rating. Br J Med Psychol. 1959;32(1):50-55.

48. Higgins JPT, Altman DG. Assessing risk of bias in included studies. In: Higgins JPT, Green S, editors. Cochrane Handbook for Systematic Reviews of Interventions. Version 5.1.0 [updated March 2011]. The Cochrane Collaboration; 2009.

49. Cipriani A, Furukawa TA, Salanti G, et al. Comparative efficacy and acceptability of 12 new-generation antidepressants: a multipletreatments meta-analysis. Lancet. 2009;373(9665):746-758.

50. Papakostas GI. Tolerability of modern antidepressants. J Clin Psychiatry. 2008;69 Suppl E1:8-13.

51. Deeks JJ, Higgins JPT, Altman DG. Analysing data and undertaking meta-analyses. In: Higgins JPT, Green S, editors. Cochrane Handbook for Systematic Reviews of Interventions. Version 5.1.0 [updated March 2011]. The Cochrane Collaboration; 2009.

52. Wiebe N, Vandermeer B, Platt RW, Klassen TP, Moher D, Barrowman NJ. A systematic review identifies a lack of standardization in methods for handling missing variance data. J Clin Epidemiol. 2006;59(4): $342-353$.

53. Sterne JAC, Egger M, Moher D. Addressing Reporting Biases. In: Higgins JPT, Green S, editors. Cochrane Handbook for Systematic Reviews of Interventions. Version 5.1.0 [updated March 2011]. The Cochrane Collaboration; 2009.

54. Endicott J, Svedsater H, Locklear JC. Effects of once-daily extended release quetiapine fumarate on patient-reported outcomes in patients with generalized anxiety disorder. Neuropsychiatr Dis Treat. 2012;8: 301-311.

55. Montgomery SA, Locklear JC, Svedsater H, Eriksson H. Efficacy of once-daily extended release quetiapine fumarate in patients with different levels of severity of generalized anxiety disorder. Int Clin Psychopharmacol. 2014;29(5):252-262.
56. Sheehan DV, Svedsater H, Locklear JC, Eriksson H. Effects of extended-release quetiapine fumarate on long-term functioning and sleep quality in patients with Generalized Anxiety Disorder (GAD): data from a randomized-withdrawal, placebo-controlled maintenance study. J Affect Disord. 2013;151(3):906-913.

57. AstraZeneca. Safety \& Efficacy Study of Quetiapine Fumarate $\left(\right.$ SEROQUEL $^{\circledR}$ ) vs Placebo in Generalized Anxiety Disorder (TITANIUM). Available fom: https://clinicaltrials.gov/ct2/show/NCT00329264. NLM identifier: NCT00329264. Accessed October 18, 2015.

58. AstraZeneca. Efficacy and Safety Study of Seroquel SR in the Treatment of Generalized Anxiety Disorder (SILVER). Available from: https://clinicaltrials.gov/ct2/show/NCT00322595. NLM identifier: NCT00322595. Accessed October 18, 2015.

59. AstraZeneca. Safety \& Efficacy Study of Quetiapine Fumarate (SEROQUEL ${ }^{\circledR}$ ) vs Placebo \& Active Control in Generalized Anxiety Disorder (GOLD). Available from: https://clinicaltrials.gov/ct2/ show/NCT00329446. NLM identifier: NCT00329446. Accessed October 18, 2015.

60. Merideth C, Cutler A, Neijber A, She F, Eriksson H. Extended release quetiapine fumarate monotherapy for generalized anxiety disorder (gad): a randomized, placebo and escitalopram-controlled study. World Psychiatry. 2009;8(Suppl 1):215 meeting: April 1-4, 2009; Florence, Italy.

61. Brawman-Mintzer O, Nietert PJ, Rynn M, Rickels K. Quetiapine monotherapy in patients with generalized anxiety disorder. Paper presented at: 46th Annual NCDEU (New Clinical Drug Evaluation Unit) meeting; June 12-15, 2006; Boca Raton, FL.

62. Sheehan DV, Svedsater H, Locklear J, Eriksson H. Effects of extended release quetiapine fumarate on long-term functioning and sleep quality in patients with generalized anxiety disorder (GAD) [conference abstract]. Paper presented at: 163rd Annual Meeting of the American Psychiatric Association; May 22-26, 2010; New Orleans, LA.

63. Wu WY, Wang G, Ball SG, Desaiah D, Ang QQ. Duloxetine versus placebo in the treatment of patients with generalized anxiety disorder in China. Chin Med J (Engl). 2011;124(20):3260-3268.

64. Goodman WK, Bose A, Wang Q. Treatment of generalized anxiety disorder with escitalopram: pooled results from double-blind, placebocontrolled trials. J Affect Disord. 2005;87(2-3):161-167.

65. Papadimitriou GN, Linkowski P. Sleep disturbance in anxiety disorders. Int Rev Psychiatry. 2005;17(4):229-236.

66. Stein DJ, Lopez AG. Effects of escitalopram on sleep problems in patients with major depression or generalized anxiety disorder. Adv Ther. 2011;28(11):1021-1037.

67. Dolder CR, Nelson MH, Iler CA. The effects of mirtazapine on sleep in patients with major depressive disorder. Ann Clin Psychiatry. 2012; 24(3):215-224.

68. Lenze EJ, Rollman BL, Shear MK, et al. Escitalopram for older adults with generalized anxiety disorder: a randomized controlled trial. JAMA. 2009;301(3):295-303.
Drug Design, Development and Therapy

\section{Publish your work in this journal}

Drug Design, Development and Therapy is an international, peerreviewed open-access journal that spans the spectrum of drug design and development through to clinical applications. Clinical outcomes, patient safety, and programs for the development and effective, safe, and sustained use of medicines are a feature of the journal, which

\section{Dovepress}

has also been accepted for indexing on PubMed Central. The manuscript management system is completely online and includes a very quick and fair peer-review system, which is all easy to use. Visit http://www.dovepress.com/testimonials.php to read real quotes from published authors. 